\title{
Evaluation of Evapotranspiration over a Semiarid Region Using Multiresolution Data Sources
}

\author{
SAJAD JAMSHIDI \\ Department of Water Engineering, Shiraz University, Shiraz, Iran, and Department of Agronomy, \\ Purdue University, West Lafayette, Indiana \\ SHAHROKH ZAND-PARSA \\ Department of Water Engineering, Shiraz University, Shiraz, Iran \\ MOJTABA PAKPARVAR \\ Fars Agricultural and Natural Resources Research and Education Center, Shiraz, Iran \\ DEV NiYOGI \\ Department of Agronomy, and Department of Earth, Atmospheric, and Planetary Sciences, \\ Purdue University, West Lafayette, Indiana
}

(Manuscript received 25 April 2018, in final form 19 March 2019)

\begin{abstract}
Evapotranspiration (ET) estimation is important for water management decision tools. In this study, different ET data with varying resolution, accuracy, and functionality were reviewed over a semiarid, datasparse region in southern Iran. Study results showed that the widely used reanalysis and Moderate Resolution Imaging Spectroradiometer (MODIS) datasets have relatively high uncertainty and underestimated ET over the sparse heterogeneous landscape. On the other hand, fine-resolution ET datasets using Landsat imagery with Mapping Evapotranspiration at High Resolution with Internalized Calibration (METRIC) and Surface Energy Balance System (SEBS) algorithms, yielded high accuracy. Evaluation of METRIC and SEBS models in estimating seasonal crop water use showed a mean absolute error of $5 \%$ and $13 \%$, respectively. The Satellite Application Facility on Climate Monitoring (CMSAF) data were used as radiation input to the models and were found to be a representative data source with daily average RMSE of $70 \mathrm{~W} \mathrm{~m}^{-2}$. An average crop coefficient $K_{c}$ was estimated for the region and was obtained as 0.77 . The study proposes and applies a hybrid framework that uses reference ET from simple diagnostic models (such as the REF-ET tool) and calculates actual ET by using the satellite-derived regionally and locally representative $K_{c}$ values. The ET estimates generated with the framework were regionally representative and required low computational resources. The study findings have the potential to provide practical guidance to local farmers and water managers to generate useful and usable decision-making tools, especially for ET assessments in the study region and other data-sparse areas.
\end{abstract}

\section{Introduction}

The motivation for this study stems from the need that has been highlighted in agricultural regions that dominate the semiarid areas such as southern Iran and the broader Middle East-North Africa (MENA) region (Rockström et al. 2009). These regions suffer from water scarcity and paradoxically have agriculture as the main

Corresponding author: Prof. Dev Niyogi, climate@purdue.edu economy (Esmaeili and Vazirzadeh 2009; Droogers et al. 2012). The per capita freshwater availability for Iran was estimated to be below $1500 \mathrm{~m}^{3} \mathrm{yr}^{-1}$ (the water scarcity threshold) in 2030; the value is currently less than $200 \mathrm{~m}^{3} \mathrm{yr}^{-1}$ in countries like Yemen and Jordan within the MENA region (Faramarzi et al. 2009; Droogers et al. 2012). The agricultural economy is also the driver for maintaining geopolitical stability in these regions (Voss et al. 2013). As such, the region's population is experienced in agriculture but is only modestly skilled 


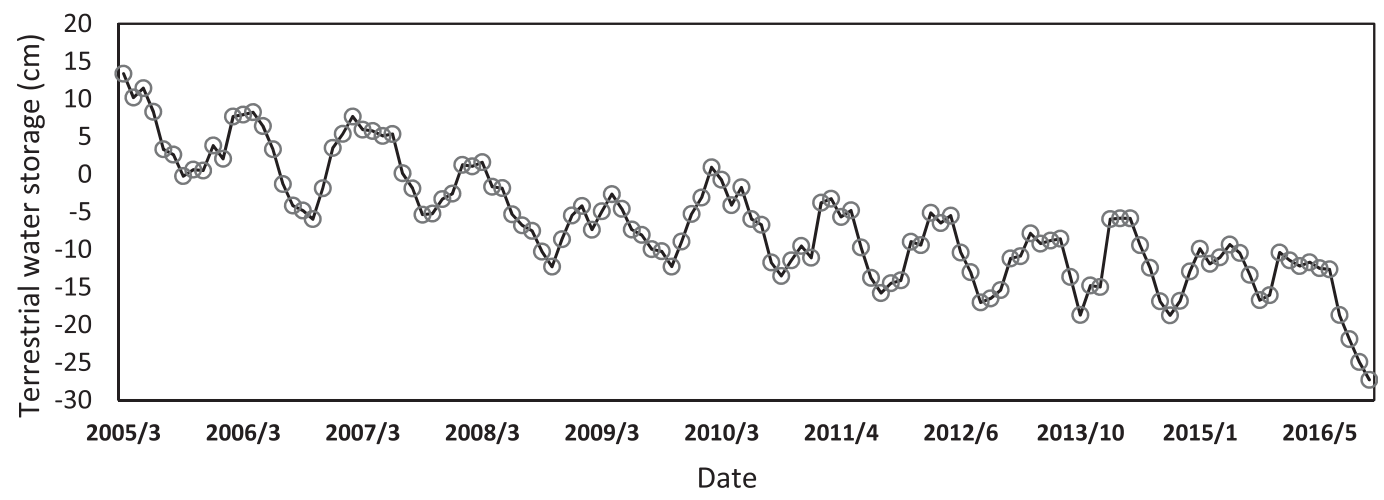

FIG. 1. Trend in groundwater depletion from 2005 to 2017 based on GRACE data (available at http://grace.jpl.nasa.gov).

in the use of technology needed for water management applications (Allan and Allan 2002). The agricultural population is also challenged by the lack of formal education, and several projects have been looking at such semiarid and the MENA region as a locale where future sustainability and stability is linked to water access and management (Haddadin 2001; Hakimian 2003). The groundwater table in these regions has been declining, and local knowledge suggests this decline is due to overirrigation. Figure 1 shows the changes in the groundwater from 2005 to 2017 based on Gravity Recovery and Climate Experiment (GRACE) data, centered over the region. While there is the seasonal recharge, a long-term steady decline in the groundwater storage field is evident. As a result, the region continues to have increased water vulnerability due to preexisting limited water availability and exacerbating groundwater decline. Excessive groundwater pumping has caused regulations to be enacted, with reports of a potential gray market for water permits (El Kharraz et al. 2012) leading to land abandonment and cultural and geopolitical instability. Moreover, the recent climate variability with instances of prolonged and severe drought has caused further stress on the region's ability to sustain itself (Nazemosadat and Ghasemi 2004; Raziei et al. 2009).

From the hydrometeorological perspective, the problem boils down to quantifying the water budget in this area. There is relatively good information becoming available regarding rainfall occurrences and availability based on some in situ and satellite measurements (Yatagai et al. 2008; Tabari and Talaee 2011). The core issue is that local agencies need a water management plan in conjunction with a correct understanding of the hydrological cycle, along with tools for understanding crop water use and sufficient irrigation. To that end, one important piece of information that the local agencies need is a simple but reliable estimate of the regional evapotranspiration (ET) that can be used in terms of designing decision tools at local and regional scales. ET estimates are important to improve decision-making tools, detect crop stress, refine irrigation scheduling, and manage of water resources at the watershed scale (Gibson et al. 2013; Kongo and Jewitt 2006; Kamali and Zand-Parsa 2017).

For ET estimation, a number of approaches are available. These include direct measurements like lysimeters and eddy covariance techniques (Baldocchi 2003; Aubinet 2008, Liu et al. 2013), or estimations by mathematical, empirical, or analytical approaches (Wright 1982; Hargreaves and Samani 1985; Allen et al. 1998). To overcome temporal and spatial field scale inherent in traditional parametric methods, a number of studies have also developed remote sensing-based algorithms utilizing surface energy balance concepts to retrieve ET for a regional scale either by modeling (e.g., Bastiaanssen et al. 1998; Su 2002; Allen et al. 2007; Irmak et al. 2013) or satellite products of ET estimates (Anderson et al. 2011; Mu et al. 2011; Vinukollu et al. 2011; Senay et al. 2011; Jamshidi et al. 2019). Atmospheric reanalysis data have also been used in a number of studies (Fall et al. 2010; Trenberth et al. 2011; Weedon et al. 2014), but in regard to estimating ET at regional and local scales, relatively few studies exist and most are based on physical and empirical approaches or using satellite measurement (Wang et al. 2011; Mao and Wang 2017).

In this study, we assessed the different ET data sources that provide evapotranspiration from gridded datasets such as reanalysis to fine-resolution satellite datasets for the Gareh Bygone Plain (GBP) in southern Iran. It should be noted that, due to the paucity of in situ data in the region, the spatial scale of this study is limited to the GBP, the landscape and climate of which is broadly representative of the southern Iran regions. An implicit objective is to understand the reliability and utility of these large-scale datasets to undertake decisions for regions with small landholdings and heterogeneous land cover. Thus, the study aims to assess and compare the ET estimates that emerge from the comparison 


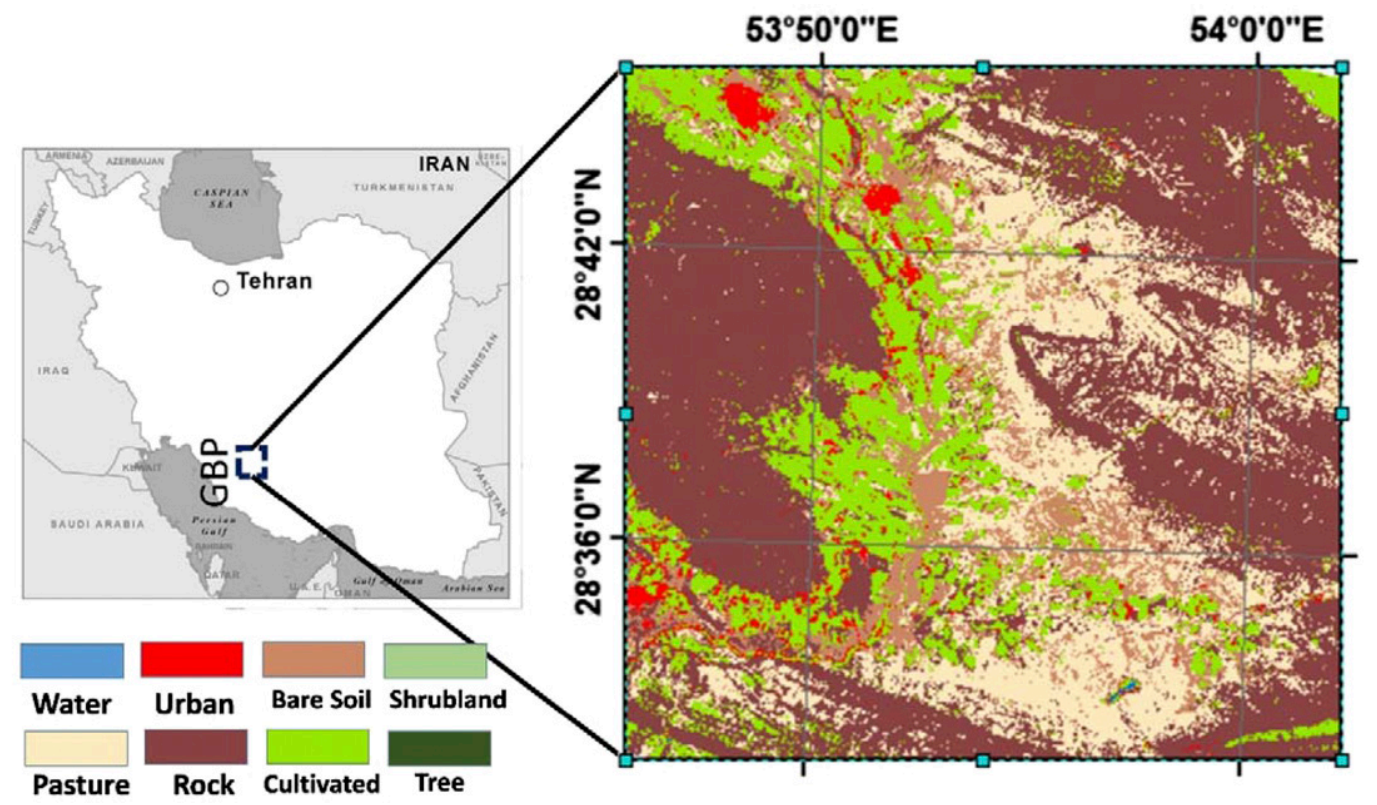

FIG. 2. Location of the study site in Iran and simplified map of main land use.

among gridded products, satellite-based methods, and in situ measurements for the study region. The second objective is to highlight a simple hybrid methodology that emerged from the result based on comparisons with observations to provide a locally representative and reliable ET that can ultimately help better irrigation mapping and control, or water management at the local scale. The performance of such methodology for developing reliable ET datasets was also evaluated. Accordingly, Mapping Evapotranspiration at High Resolution with Internalized Calibration (METRIC) and Surface Energy Balance System (SEBS) models were used in estimating seasonal crop water use in farmlands (mainly winter wheat and forage corn), and the results were compared with in situ measurements. Considering the importance of a reliable shortwave incoming solar radiation (SISR) source in ET calculations, an ancillary objective of this study includes the evaluation of different SISR datasets for using in surface energy balance methods (i.e., METRIC and SEBS) in southern Iran as an example of a data-sparse region.

\section{Data and methods}

\section{a. Study site}

The GBP is an area of 18000 ha located south of the Zagros Mountains in southern Iran between $28^{\circ} 35^{\prime} \mathrm{N}$ and $53^{\circ} 53^{\prime} \mathrm{E}$. The altitude of the GBP ranges between 1120 and $1160 \mathrm{~m}$ MSL (Fig. 2). The mean annual precipitation of the GBP region is $219 \mathrm{~mm}$, typically occurring from December to March, with the exception of few events in summer (June-July). The air temperature peaks to $40^{\circ}-46^{\circ} \mathrm{C}$ between July and August and then drops to from $-1^{\circ}$ to $-6^{\circ} \mathrm{C}$ between January and February. Weather data for this region are typically available from the Gareh Bygone and the Fasa weather stations, and are located about $45 \mathrm{~km}$ from the GBP. Sparse shrublands, rangelands, and bare soil are the main land covers over GBP. The landscape and climate of this area is broadly representative of the southern/ southeast Iran regions.

In the study area, wheat is the dominant crop type. The region typically has an annual crop-fallow rotation system, but sometimes fallow is replaced by barley or cotton in winter. For summer, watermelon and cantaloupe are the main crops, and wheat, barley, or forage corn are grown in rotation (Table 1 ).

\section{b. Evapotranspiration datasets and methods}

Performance of ET models is intimately linked with the geographical scale at which the model is being applied and the datasets available (Fisher et al. 2011). The model use is also linked to available input data. The validation of ET products is dependent upon the spatial resolution (Liang et al. 2004), causing uncertainties in the results from studies, showing good or poor results depending on the season and location. In this study, the choice of the datasets was governed by the data availability and accessibility. Figure 3 shows the spatial resolution and the conceptual view of the ease of access to this information from the user's perspective. In this regard, a reanalysis dataset as a continuous, gridded 
TABLE 1. Vegetation characteristics (Pakparvar et al. 2014). Winter crops: wheat (Triticum aestivum) or barley (Hordeum vulgare); midsummer crops: watermelon (Citrullus lanatus), melon (Cucumis melon), cantaloupe (Cucumis melo var. cantalupensis); late summer crop: forage corn (Zea mays).

\begin{tabular}{|c|c|c|c|c|c|c|c|}
\hline \multirow[b]{2}{*}{ Land use } & \multirow[b]{2}{*}{ Main crops } & \multicolumn{3}{|c|}{ Agronomic dates } & \multicolumn{2}{|c|}{ Irrigation } & \multirow[b]{2}{*}{ Average yield $\left(\mathrm{tha}^{-1}\right)$} \\
\hline & & Sowing & Harvesting & Max green & Methods & Depth (mm) & \\
\hline \multirow[t]{3}{*}{ Farmland } & Winter & December & Early June & Mid-March & Surface & $400-570$ & $4-5$ \\
\hline & Midsummer & 20-30 Feb & Mid-August & Early August & Furrow & $1100-1300$ & Different \\
\hline & Late summer & Mid-August & 5-10 Nov & 20-25 Sep & Furrow & $900-1100$ & $35-45$ \\
\hline
\end{tabular}

product is relatively easy to access but is at the largest scale (i.e., coarse spatial resolution). Following the reanalysis, Moderate Resolution Imaging Spectroradiometer (MODIS) ET datasets provide moderately easy access as well as spatial resolution. Landsat-based processing with METRIC and SEBS involves computational processing and some level of sophistication; nevertheless, it provides high-resolution datasets. There are also different types of datasets possible from in situ observations that can be used in simple parametric equations and models or tools such as REF-ET (Allen 2000). On the other end, in situ observations have high local usability but have difficulty providing continuous measurements. Each of these datasets and the methodology used in terms of data processing is described in this section.

\section{1) ReAnAlysis}

NCEP, ERA-Interim, and ERA-5 are used in this study (Bengtsson et al. 2004; Schmidt et al. 2006; Weedon et al. 2014). The NCEP reanalysis covers 4 times daily, daily, and monthly values with T62 Gaussian grid $(192 \times 94$ points $)$. The First Global Atmospheric
Research Program (GARP) Global Experiment (FGGE) was the first reanalysis produced in the 1980s, followed by ERA-15, ERA-40, and most recently ERA-Interim and ERA-5. NCEP reanalysis uses a twice-a-day, fourdimensional variational analysis (4D-Var) approach. ERA-Interim data are generated at a spatial resolution of $80 \mathrm{~km}$, and ERA-5 provides data at a considerably higher spatial and temporal resolution, with hourly analysis fields at a spatial resolution of $31 \mathrm{~km}$.

Data were retrieved from www.ecmwf.int in netCDF format. In reanalysis datasets we calculate the evaporation fields using latent heat flux $L_{H}$ and latent heat of vaporization $\left(2.45 \mathrm{~J} \mathrm{~kg}^{-1}\right)$ according to Lorenz and Kunstmann (2012).

\section{2) MODIS}

The second data source for this data-sparse region is MODIS, on board the Terra and Aqua satellites. In particular, MODIS evapotranspiration data based on the MOD16 algorithm (Mu et al. 2011) were used. The surface energy portioning process and atmospheric drivers on ET are considered in the MOD16 algorithm.

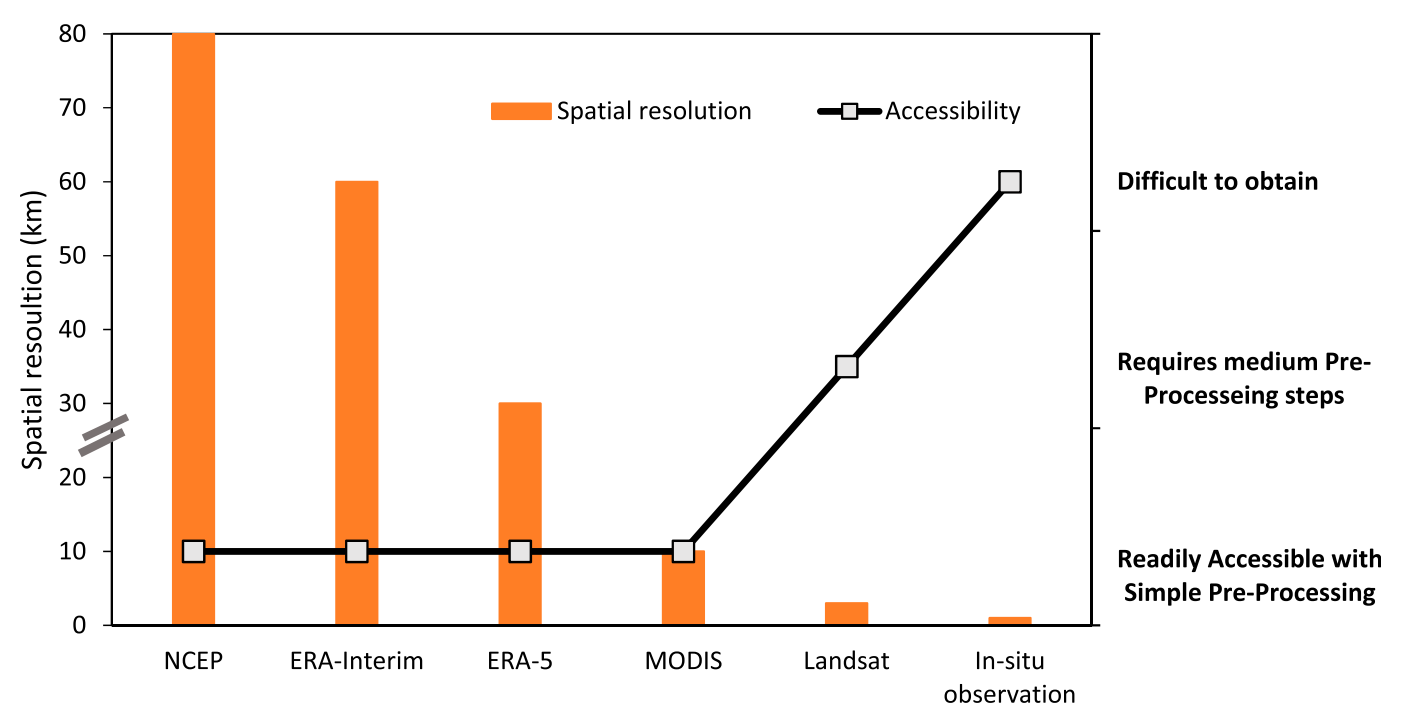

FIG. 3. Spatial resolution and ease of access to data sources from the user's perspective. 
Land cover data, fraction of photosynthetic active radiation (FPAR), and leaf area index (LAI) as well as global surface meteorology are the inputs used in the algorithm to generate global ET data products (Mu et al. 2007, 2011).

The MODIS ET products include 8-day, monthly, and annual actual ET (AET), latent heat flux (LE), potential ET (PET), and potential LE (PLE) datasets. Spatial resolution of version 5 products is at $1 \mathrm{~km}$, which increased to a nominal $500 \mathrm{~m}$ in version 6 .

MODIS AET datasets were obtained from earthdata.nasa.gov in HDF format and first needed to be georeferenced and reprojected. The ET values from MODIS and reanalysis for a 5-yr period from 2009 to 2014 were extracted from the grid and pixels over GBP.

\section{3) LANDSAT-BAsed ET}

To obtain ET at a finer spatial resolution, Landsat data were used. Landsat is a joint program of the USGS and NASA that produces multispectral and thermal data with 30-m resolution. We processed Landsat data as input for two surface energy balance models: METRIC (Allen et al. 2007) and SEBS (Su 2002). These models were run using in-house code using ERDAS IMAGINE model maker tools. Due to a data gap issue in Landsat 7, the Landsat 5 Thematic Mapper (TM5) was used.

The SEBS and METRIC models are based on the surface energy balance equation:

$$
\mathrm{LE}+H=R_{n}-G,
$$

where LE is the latent energy consumed by $\operatorname{ET}\left(\mathrm{W} \mathrm{m}^{-2}\right)$, $R_{n}$ is the net radiation $\left(\mathrm{W} \mathrm{m}^{-2}\right), G$ is the soil heat flux $\left(\mathrm{W} \mathrm{m}^{-2}\right)$, and $H$ is the sensible heat flux $\left(\mathrm{W} \mathrm{m}^{-2}\right)$. The net radiation can be calculated as the difference between incoming and outgoing shortwave and longwave radiation:

$$
R_{n}=(1-\alpha) R_{s, \text { in }}+\varepsilon R_{l, \text { in }}-\sigma \varepsilon T^{4},
$$

where $R_{s, \text { in }}$ is the incoming shortwave (solar) radiation $\left(\mathrm{W} \mathrm{m}^{-2}\right), \alpha$ is the shortwave albedo $R_{l, \text { in }}$ is the incoming longwave (or thermal) radiation $\left(\mathrm{W} \mathrm{m}^{-2}\right), \sigma$ is the StefanBoltzmann constant, $5.67 \times 10^{-8}\left(\mathrm{~W} \mathrm{~m}^{-2} \mathrm{~K}^{-4}\right), \varepsilon$ is the surface emissivity, and $T$ is the air temperature (K).

\section{(i) METRIC}

The model was developed based on the principles and techniques used in the Surface Energy Balance of Land (SEBAL) model and relies upon albedo and land surface temperature data to model energy fluxes. The model computes $G$ as a ratio $G / R_{n}$ using an empirical equation (Allen et al. 2007) as follows:

$$
\begin{aligned}
\frac{G}{R_{n}}= & \left(T_{s}-273.15\right) \times(0.0038+0.0074 \alpha) \\
& \times\left(1-\mathrm{NDVI}^{4}\right),
\end{aligned}
$$

where $T_{s}$ is surface temperature (K) and NDVI is the normalized differential vegetation index.

Sensible heat flux is a function of air density $\rho_{\text {air }}\left(\mathrm{kgm}^{-3}\right)$, the specific heat constant of air at constant pressure $\left(C_{p}=1004 \mathrm{~J} \mathrm{~kg}^{-1} \mathrm{~K}^{-1}\right)$, the aerodynamic resistance $r_{\mathrm{ah}}\left(\mathrm{sm}^{-1}\right)$, and the temperature difference $d T(\mathrm{~K})$, typically between 0.1 and $2 \mathrm{~m}$ above the canopy (Bastiaanssen et al. 1998):

$$
H=\rho_{\text {air }} \times C_{p} \times \frac{d T}{r_{\mathrm{ah}}} .
$$

An iterative solution is required to compute $H$ because $d T$ is initially unknown. The first iteration is completed assuming neutral atmospheric stability. To determine $d T$ at all the pixels, a linear relationship is assumed to exist between $d T$ and the radiometric surface temperature $T_{s}$ :

$$
d T=a+b T_{s},
$$

where $a$ and $b$ are empirical coefficients estimated based on two anchor pixels that define the upper (hot) and lower (cold) bounds of the sensible heat flux. The METRIC model equations are internally calibrated at these two limiting conditions using an iterative process. Hot pixels are located in bare, dry agricultural fields with either no residual soil moisture such that ET is assumed to be zero, or as a result of a wetting event, there might be residual evaporation from soil so a nonzero value of ET can be assumed. Thus in METRIC,

$$
d T_{\text {hot }}=\frac{H_{\text {hot }} \times r_{\text {ah }}}{\rho_{\text {air }} \times C_{p}} \stackrel{\text { if } \mathrm{LE}_{\text {hot }}=0}{\rightarrow} d T_{\text {hot }}=\frac{\left(R_{n}-G\right) \times r_{\text {ah }}}{\rho_{\text {air }} \times C_{p}} .
$$

"Cold" pixels are located in well irrigated, fully vegetated agricultural fields where there is no water stress and maximum ET occurs. The resulting equation is

$$
\begin{aligned}
d T_{\text {cold }} & =\frac{H_{\text {cold }} \times r_{\text {ah }}}{\rho_{\text {air }} \times C_{p}} \stackrel{\text { Substituting } H}{\rightarrow} d T_{\text {cold }} \\
& =\frac{\left(R_{n}-G-1.05 \mathrm{ET}_{\text {ref }}\right) \times r_{\text {ah }}}{\rho_{\text {air }} \times C_{p}} .
\end{aligned}
$$

The calculated values for $d T$ and $T_{s}$ for each end pixel are then substituted back into Eq. (4) to determine parameters $a$ and $b$. Using this relationship, $d T$ and $H$ can be estimated for each pixel in the scene. Choosing these 
pixels requires experience and expertise on the part of the user and can introduce uncertainty (Long and Singh 2013). In this study, hot and cold reference pixels were selected in a predetermined way to fulfill the required criteria. Moreover, they were verified to be for agricultural fields, avoiding villages, roads, or any other land cover.

The instantaneous ET (ET inst $)$ is then determined as

$$
\mathrm{ET}_{\text {inst }}=3600 \frac{\mathrm{LE}}{\lambda} \text {. }
$$

To extrapolate daily $\mathrm{ET}\left(\mathrm{ET}_{24}\right)$ from $\mathrm{ET}_{\text {inst }}$, it is assumed that the reference ET fraction $\left(\mathrm{ET}_{\mathrm{rF}}\right)$ at the Landsat overpass moment equals the average $\mathrm{ET}_{\mathrm{rF}}$ throughout that day, as calculated by

$$
\mathrm{ET}_{\mathrm{rF}}=\frac{\mathrm{ET}_{\text {inst }}}{\mathrm{ET}_{\mathrm{ref}}} .
$$

The $\mathrm{ET}_{24 \mathrm{ref}}$ is estimated using the Penman-Monteith equation (Allen et al. 1998). Actual $\mathrm{ET}_{24}$ is then calculated by

$$
\mathrm{ET}_{24}=\mathrm{ET}_{\mathrm{rF}} \times \mathrm{ET}_{24 \mathrm{ref}} .
$$

A simple interpolation function is used to interpolate between scenes to retrieve monthly and seasonal ET.

\section{(ii) $S E B S$}

SEBS has been used over different landscapes and spatial scales using Landsat, ASTER, and MODIS satelliteacquired data (Su et al. 2005; Van der Kwast et al. 2009). In SEBS, similar to METRIC, $G$ was estimated as a fraction of net radiation as

$$
G=R_{n}\left[\Gamma_{c}+\left(1-f_{c}\right)\left(\Gamma_{s}-\Gamma_{c}\right)\right] .
$$

For full vegetation canopy $\Gamma_{c}=0.05$, and for bare soil $\Gamma_{S}=0.315$ (Kustas and Daughtry 1990). Computing the surface energy balance with the SEBS algorithm was based on the determination of the relative evaporation fraction $\left(\mathrm{EF}_{r}\right)$, which is the partition of the available energy between sensible and latent. To determine the $\mathrm{EF}_{r}$ fraction, two limits were considered. In the dry-limit condition, the soil moisture is limited, and latent heat $\lambda E$ becomes zero and sensible heat flux is at its maximum value $H_{\text {dry }}$ :

$$
H_{\mathrm{dry}}=R_{n}-G
$$

At the wet-limit, sensible heat flux is minimal $H_{\text {wet }}$ yielding

$$
H_{\text {wet }}=R_{n}-G-\lambda E_{\text {wet }} .
$$

The $\mathrm{EF}_{r}$ can be then evaluated as

$$
\mathrm{EF}_{r}=\frac{\lambda E}{\lambda E_{\mathrm{wet}}}=1-\frac{H-H_{\mathrm{wet}}}{H_{\mathrm{dry}}-H_{\mathrm{wet}}} .
$$

The $H_{\text {dry }}$ was obtained by Eq. (12) while $H_{\text {wet }}$ was given by substitution of Eq. (13) to a combination equation similar to the Penman-Monteith equation proposed by Menenti (1984). The evaporative fraction was eventually obtained as

$$
\mathrm{EF}_{r}=\frac{\lambda E}{R_{n}-G}=\frac{\mathrm{EF}_{r} \times \lambda E_{\text {wet }}}{R_{n}-G} .
$$

If the net radiation for $24 \mathrm{~h} \overline{R_{n}}$ was estimated from daily meteorological parameters, then the average daily evapotranspiration could be calculated as

$$
\mathrm{ET}_{24}=8.64 \times 10^{7} \times \Lambda \times \frac{\overline{R_{n}}-\bar{G}}{\lambda \rho w},
$$

where $\lambda$ is latent heat of vaporization $\left(2.45 \mathrm{~J} \mathrm{~kg}^{-1}\right)$ and $\rho w$ is density of water $\left(1000 \mathrm{~kg} \mathrm{~m}^{-3}\right)$. The average soil heat flux over a 24 -h period $(\bar{G})$ was assumed to be negligible (Su 2002).

As suggested by Allen et al. (2007), we used the calculated the reference ET fraction for METRIC model and evaporative fraction for the SEBS model from each Landsat image and multiplied the fraction values by the reference ET to calculate daily ET for gap days between satellite overpass dates.

\section{c. In situ measurements}

To evaluate the METRIC and SEBS models for local applications, measurements were obtained from Pakparvar et al. (2014). The data included the volume of irrigation water used in farmlands as measured for two cropping seasons from December 2009 to December 2010. Guided by the recommendations from Pakparvar et al. (2014), the amount of effective rainfall (recorded rainfall $\times 0.7)$ in the volume base was added to the calculated applied water. The study reported that $24 \%$ of total input water (irrigation + precipitation) returns to the hydrological cycle as return flow.

Over GBP two Landsat path images were available every 7-9 days with path/row designations 161/40 and $162 / 40$. To estimate the value of ET for winter and summer cropping seasons, a time series of 22 scenes between 13 January and 21 December 2010, were available and used as input to the METRIC and SEBS models. The digital elevation model (DEM) was another required input to the models and was taken from ASTER. Initial work with the models highlighted the need to update the SISR source in using METRIC and SEBS, and is described next. 
TABLE 2. List of methods used in this study to calculate $\mathrm{ET}_{r}$ using the REF-ET software.

\begin{tabular}{|c|c|c|c|}
\hline Method's name & Source & Abbreviation & $\operatorname{RSME}(\mathrm{mm})$ \\
\hline Standardized form of the ASCE Penman-Monteith & Allen (2000) & PMst & 0.79 \\
\hline Kimberly-Penman & Wright (1996) & KPen & 0.89 \\
\hline Penman (1963) & Penman (1963) & Pen & 0.89 \\
\hline FAO-56 Penman-Monteith & Allen et al. (1998) & 56 p.m. & 1.00 \\
\hline FAO-PPP-17 Penman & Frere and Popov (1979) & FP17 & 1.53 \\
\hline FAO-24 Corrected Penman & Doorenbos and Pruitt (1977) & $24 \mathrm{Pn}$ & 1.48 \\
\hline FAO-24 Radiation Method & Doorenbos and Pruitt (1977) & $24 \mathrm{Rd}$ & 1.85 \\
\hline FAO-24 Blaney-Criddle & Doorenbos and Pruitt (1977) & $24 \mathrm{BC}$ & 1.27 \\
\hline Hargreaves temperature method & Hargreaves and Samani (1985) & Harg & 1.24 \\
\hline Priestley-Taylor radiation and temperature method & Priestley and Taylor (1972) & Tylr & 2.07 \\
\hline Makkink radiation and temperature method & Makkink (1957) & Makk & 2.40 \\
\hline Turc radiation and temperature method & Turc (1961) & Turc & 1.34 \\
\hline
\end{tabular}

\section{d. Shortwave incoming solar radiation}

Accurate SISR prescription directly affects the results of energy balance models since they are the main source of energy partitioning for evapotranspiration. In datasparse regions, SISR measurements are not usually available, causing local agencies to abandon the use of surface energy balance based methods. In addition, models and equations may require adjustments considering atmospheric and climatic characteristics of the study regions (Sepaskhah and Razzaghi 2009; Noshadi and Jamshidi 2014). A reliable source providing SISR parameter eradicates such issues and enhances the accuracy of ET calculations. The SISR calculated from the formulation available in METRIC and SEBS was compared to three sources of SISR data: (i) measurements at the weather station, (ii) values obtained by CMSAF products (https://wui.cmsaf.eu), and (iii) values generated by the "r.sun" algorithm from Geographic Resources Analysis Support System (GRASS). The CMSAF website provides the Surface Solar Radiation Dataset-Heliosat (SARAH) product available from 1983 as monthly, daily, and hourly averages and covers the region $\pm 65^{\circ}$ longitude and $\pm 65^{\circ}$ latitude on a $0.05^{\circ} \times$ $0.05^{\circ}$ resolution.

\section{e. Reference ET from REF-ET tool}

Reference ET in the study area was calculated using pan evaporation measurements at the weather stations. It should be noted that reference crop is assumed to be grass with the height of $0.12 \mathrm{~m}$. The pan evaporation was related to the reference evapotranspiration by an empirically derived pan coefficient ( 0.7 for the study area) using Eq. (17):

$$
\mathrm{ET}_{r}=E_{\text {pan }} \times 0.7
$$

where $\mathrm{ET}_{r}$ is reference evapotranspiration $\left(\mathrm{mm} \mathrm{day}^{-1}\right)$ and $E_{\mathrm{pan}}$ is measured pan evaporation $\left(\mathrm{mm} \mathrm{day}^{-1}\right)$.
Daily weather data, taken from weather stations in the study area, were used in the REF-ET tool to calculate $\mathrm{ET}_{r}$. REF-ET provides standardized calculations of $\mathrm{ET}_{r}$ using 15 of the more common methods on monthly, daily, or hourly (or shorter) time steps (Allen et al. 1998). Based on data availability and the region, ET data from 12 methods (Table 2) were plotted and the results were compared with the $\mathrm{ET}_{r}$ obtained from pan evaporation at the weather stations.

\section{Results}

A broad summary of the results and the presentation of the findings is outlined. We first present a comparison of the evapotranspiration values from different sources. For this, initial comparisons were done using graphical and statistical analysis to screen and assess the qualitative similarity. The "best models" following the initial screening and the lowest RMSE values were undertaken for more analysis by estimating water use (actual ET) over the study region. The selected models were compared with ground measurements and results are discussed in section $3 b$. Crop coefficients $K_{c}$ were also estimated for the cultivated areas using the best models, and the values were compared with the literature. The objective then is to use an average $K_{c}$ value and reference ET value to get a general assessment of water usage for the landscape which is described in sections $3 \mathrm{c}$ and $3 \mathrm{~d}$.

\section{a. Comparison of evapotranspiration datasets}

A time series of derived ET from different sources was compared to $\mathrm{ET}_{r}$ calculated from measured pan evaporation at the weather stations of the region for six years from 2009 to 2014. It should be noted that because of a lack of measured $\mathrm{ET}_{a}$ datasets for the study period, we used reference ET as the basis of model comparisons. As a result, in this subsection we compared actual modeled ET against reference measured ET merely 

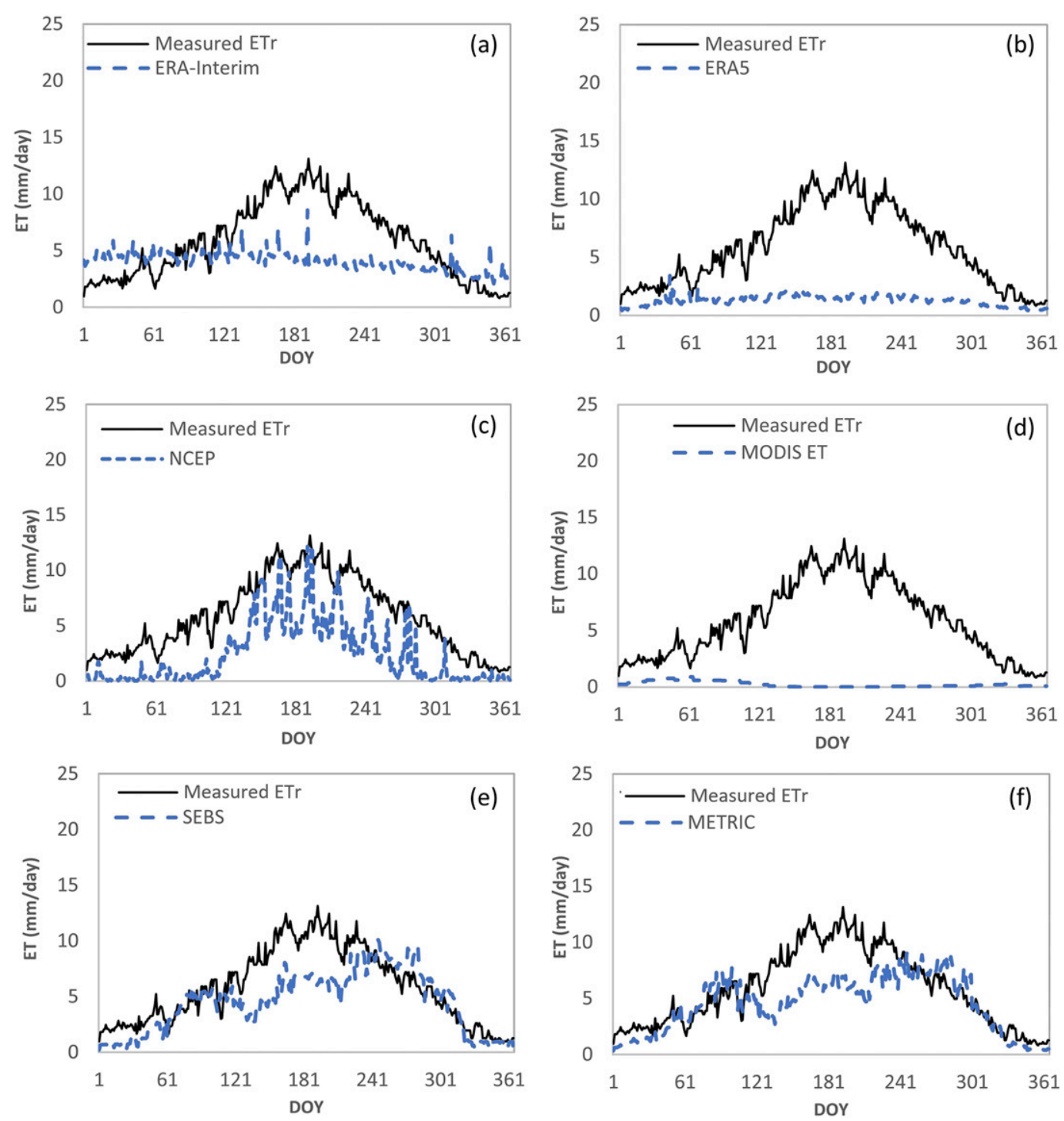

FIG. 4. Graphical comparison of $\mathrm{ET}_{r}$ resulting from pan data with $\mathrm{ET}$ values obtained from different datasets.

to highlight the qualitative similarity. This helped identify the overall accuracy of the ET data sources and aided the selection of the data source(s) with lower uncertainties for further analysis (described in the next step). The models with higher accuracy then were evaluated with in situ $\mathrm{ET}_{a}$ measurements for a growing season from 2009 to 2010. To illustrate the comparisons graphically, ET values from estimations and observations were averaged during the study period from 2009 to 2014, and plotted against day of year (Fig. 4). In addition, datasets (including all data) statistics were compared with a 1:1 line (Fig. 5), and boxplots and RMSE were computed for each dataset (Fig. 6).

ERA-Interim showed higher ET values compared to ERA-5 data, and neither showed high correlation with measured $\mathrm{ET}_{r}$ considering the RMSE value of 4.3 and $5.2 \mathrm{~mm}$, respectively. The ERA data were also unable to capture the seasonal variability in ET changes (Figs. 4 and 5a,b). The grid from ERA-5 and ERA-Interim that covers the study domain (GBP) primarily contains sparse vegetation and some agricultural regions. As a result, the vegetation fraction was small and caused the actual ET values to be notably small as compared to the observations and also did not exhibit any temporal changes due to the lack of phenology. The grid from ERA-Interim, on the other hand, is able to represent a larger fraction of agricultural landscapes, and yielded higher values of ET compared to those obtained from ERA-5. Therefore, not surprisingly, different grids from different data sources resulted in different ET values 

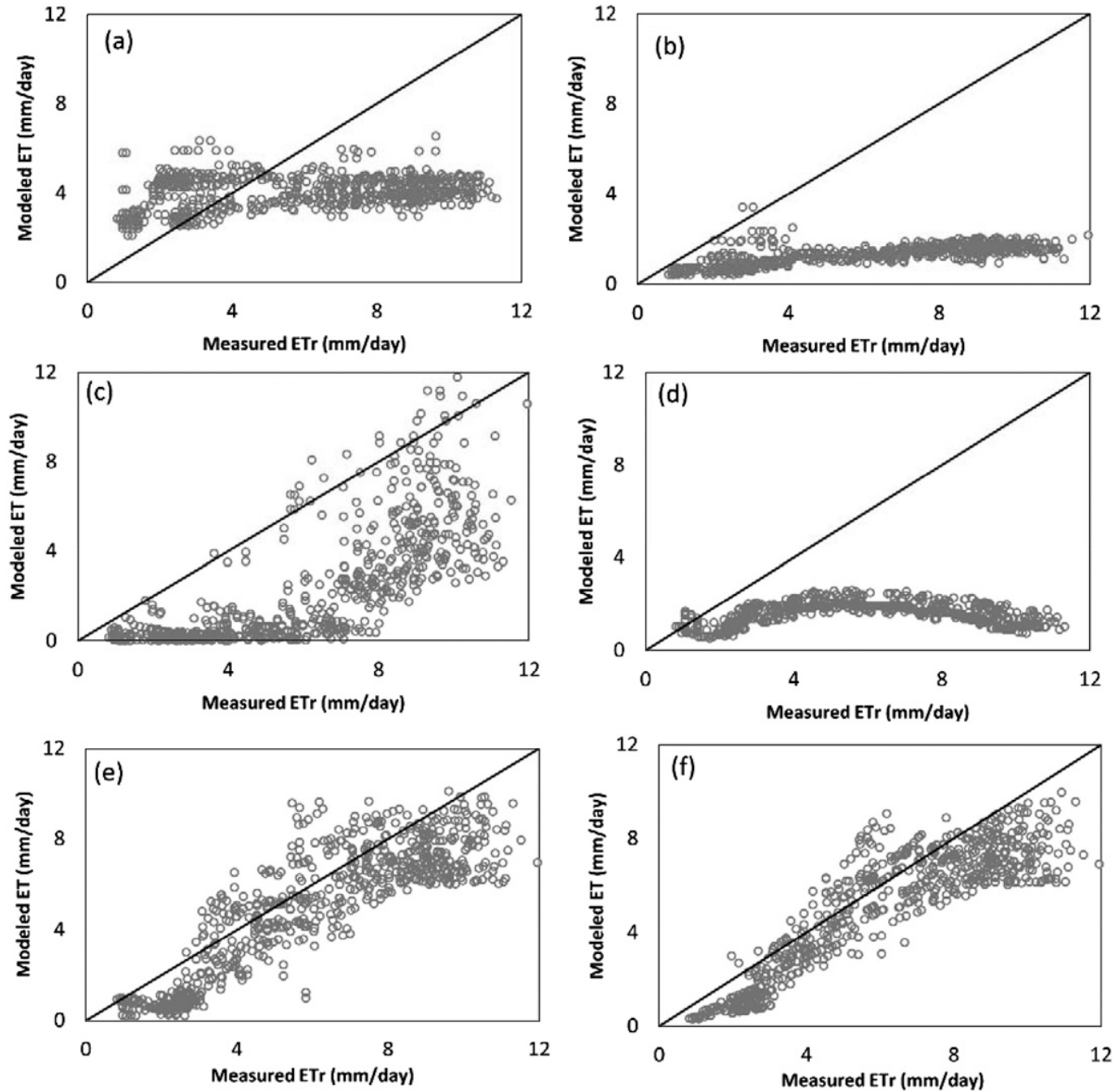

FIG. 5. Statistical comparison of $\mathrm{ET}_{r}$ resulting from pan data and ET values obtained from different datasets with 1:1 line.

because of the predominant land covers represented in the datasets. The NCEP reanalysis-based ET value also underestimated ET, but it could capture the relative spatiotemporal pattern as compared to ERA data with a better RMSE value of $3.01 \mathrm{~mm}$ (Figs. 4, 5c). Due to the coarse spatial resolution of NCEP datasets, the grid covering GBP also included some dense vegetated area with cooler climate. Therefore, the difference between two estimates was expected; however, in cold months including January, February, November, and December, the ET derived from NCEP was near zero. Generally, for small domains, the ET rate estimation is relatively simple and can be calculated with meteorological data rather than using gridded products. In this regard, our results indicated that if reanalysis data were desired, NCEP reanalysis ET data fields could indeed be more suitable for studies, especially over large domains.
Derived ET values from MODIS products are classified as those from vegetated and nonvegetated pixels. Nonvegetated pixels did not yield any ET. Sparse vegetation and a mixture of bare soil and farmlands increased the bias, causing the ET from vegetated pixels to be significantly lower with an RMSE of $5.23 \mathrm{~mm}$ (Figs. 4, 5d). Some studies have addressed the issue of uncertainty in the MODIS ET and found it to be around $25 \%$ (Mu et al. 2011; Ghilain et al. 2011). Kiptala et al. (2013) applied MOD16 algorithm to a heterogeneous landscape in eastern Africa and reported relatively modest accuracy with $R^{2}$ of $32 \%$ and MAE of $28 \%$. $\mathrm{Hu}$ et al. (2015) evaluated MOD16 from MODIS over Europe, and stated that ET data were consistent with eddy covariance measurements over most of Europe except for the semiarid regions where the ET values were notably underestimated. Trambauer et al. (2014) 


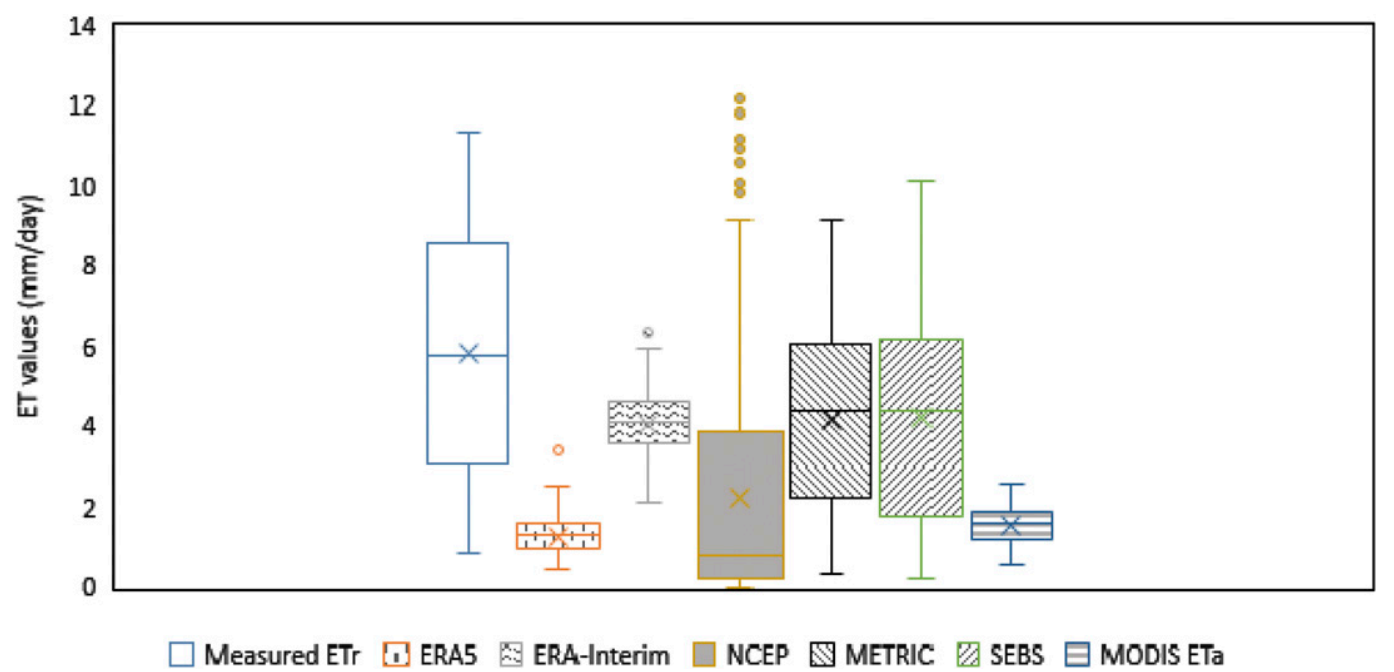

FIG. 6. Boxplot representation of ET values for each dataset in comparison with measured $\mathrm{ET}_{r}$ data.

also reported MOD16 values underestimated $\mathrm{ET}_{a}$ in the semiarid and arid Mediterranean, Sahel, and southern Africa regions and were not correlated with other products. This issue of poor accuracy in estimating ET over arid and semiarid regions and not reflecting the characteristics of the variation in a typical doublecropping system have been addressed in other studies as well (Kim et al. 2012; Liu et al. 2013).

Figures $4,5 \mathrm{e}$, and $5 \mathrm{f}$ illustrate that METRIC and SEBS-based ET could accurately capture the variability of actual ET with RMSE of 1.6 and $1.8 \mathrm{~mm}$, respectively. The trend and variability were particularly well captured and showed good correlation with $\mathrm{ET}_{r}$. The difference between observed and modeled values can be considered reasonable since the observed values were reference ET while METRIC and SEBS estimates were actual ET. Actual ET could be lower or higher than $\mathrm{ET}_{r}$ due to different crop coefficients $K_{c}$ for different growth stages. Thus, it can be concluded that high-resolution Landsat data have the potential for calculating ET as part of the tools used for ET management of farmlands that are relatively small and where sparse vegetation is dominant. Different types of land cover were discerned in the Landsat imagery that helped reduce the bias and improve accuracy of ET products through METRIC and SEBS.

The comparisons, summarized in Fig. 6 by illustrating a boxplot for all studied models, highlight the potential of the surface energy balance-based approaches including METRIC and SEBS to provide reliable localscale information of ET. As can be noted in Fig. 6, ERA-5 and MODIS ET values were consistently only a fraction of the measurements and in the lower quartile of measured $\mathrm{ET}_{r}$. ERA-Interim yielded higher ET compared to ERA-5 and MODIS, but still had a smaller range covering only the second quartile of measured $\mathrm{ET}_{r}$ values. While NCEP reanalysis values had more variance with extreme values, nearly $75 \%$ of ET rates were within lower quartile of measured $\mathrm{ET}_{r}$. The SEBS and METRIC fields had the average values (4.20 and $4.17 \mathrm{~mm} \mathrm{day}^{-1}$, respectively) that were closest to the measurements $\left(5.7{\mathrm{~mm} d a y^{-1}}^{-1}\right.$. The ET rates, while slightly lower than the measurements, presented a similar range as seen for the measured $\mathrm{ET}_{r}$ rates. The lower mean values and the ranges calculated using the SEBS and METRIC were due to the difference expected between reference ET and actual ET. The ET obtained by using SEBS and METRIC models required moderate preprocessing, and it is postulated that it can provide output that is suitable for decision support systems in the region.

Considering better performance of the METRIC and SEBS model compared to MODIS and reanalysis data, these models were selected for further evaluation through estimating actual crop water use in local irrigated farmlands at watershed level. To make the models more applicable and representative for datasparse regions, a source of solar radiation (CMSAF SISR data) was analyzed prior to using the models (comparison details in section 3e). Embedding this modification, the seasonal crop water use resulting from METRIC and SEBS was compared with in situ measurements in Pakparvar et al. (2014).

\section{b. Comparison of METRIC and SEBS estimates with measured applied water}

Seasonal estimated actual crop evapotranspiration using METRICS and SEBS methods in the study area are presented in Table 3. For the cropping season of 
TABLE 3. Crop water consumption for the cropping season of 2009-10.

\begin{tabular}{lcccccc}
\hline \hline \multicolumn{1}{c}{ Crops } & $\begin{array}{c}\text { Area } \\
(\mathrm{ha})\end{array}$ & $\begin{array}{c}\text { Irrigation } \\
\left(\mathrm{m}^{3} \mathrm{ha}^{-1}\right)\end{array}$ & $\begin{array}{c}\text { Effective rainfall } \\
\left(\mathrm{m}^{3} \mathrm{ha}^{-1}\right)\end{array}$ & $\begin{array}{c}\text { Net water } \\
\left(\mathrm{m}^{3} \mathrm{ha}^{-1}\right)\end{array}$ & $\begin{array}{c}\text { METRIC estimation } \\
\left(\mathrm{m}^{3} \mathrm{ha}^{-1}\right)\end{array}$ & $\begin{array}{c}\text { SEBS estimation } \\
\left(\mathrm{m}^{3} \mathrm{ha}^{-1}\right)\end{array}$ \\
\hline Winter crops & 1234 & 4800 & 1000 & 5.44 & 5.66 & 4.81 \\
Summer crops & 716 & 9800 & 0 & 5.33 & 5.02 & 6.16 \\
\hline
\end{tabular}

2009-10, out of the 2000 ha of farm fields in the study area, 1234 ha were used for winter crops and 716 ha as summer crops. For winter crops, the net input water was determined as $5.434 \mathrm{Mm}^{3}$, which accounted for the $\mathrm{ET}_{a}$. Examples of actual ET maps generated for the region through the growing season are presented in Fig. 7.

METRIC and SEBS modeled cumulative ET for this period equals 5.66 and $4.81 \mathrm{Mm}^{3}$, respectively. Hence, the modeled $\mathrm{ET}_{a}$ from the two models yield $4.6 \%$ of overestimation and $11.4 \%$ of underestimation, which seemed adequate for development of regional estimates.
For the summer season, the total amount of net applied water was measured as $5.33 \mathrm{Mm}^{3}$, which accounts for the $\mathrm{ET}_{a}$ (Pakparvar et al. 2014). The water consumption for summer and winter was approximately the same because of less cultivated area in summer. The METRIC model estimated the $\mathrm{ET}_{a}$ for this period as $5.02 \mathrm{Mm}^{3}$ with $9.4 \%$ of underestimation, whereas the SEBS model estimated the amount to be $6.16 \mathrm{Mm}^{3}$, yielding $15.6 \%$ overestimation. Lower accuracy for the summer cropping season by the METRIC model was mostly due to the lack of ground information regarding land cover
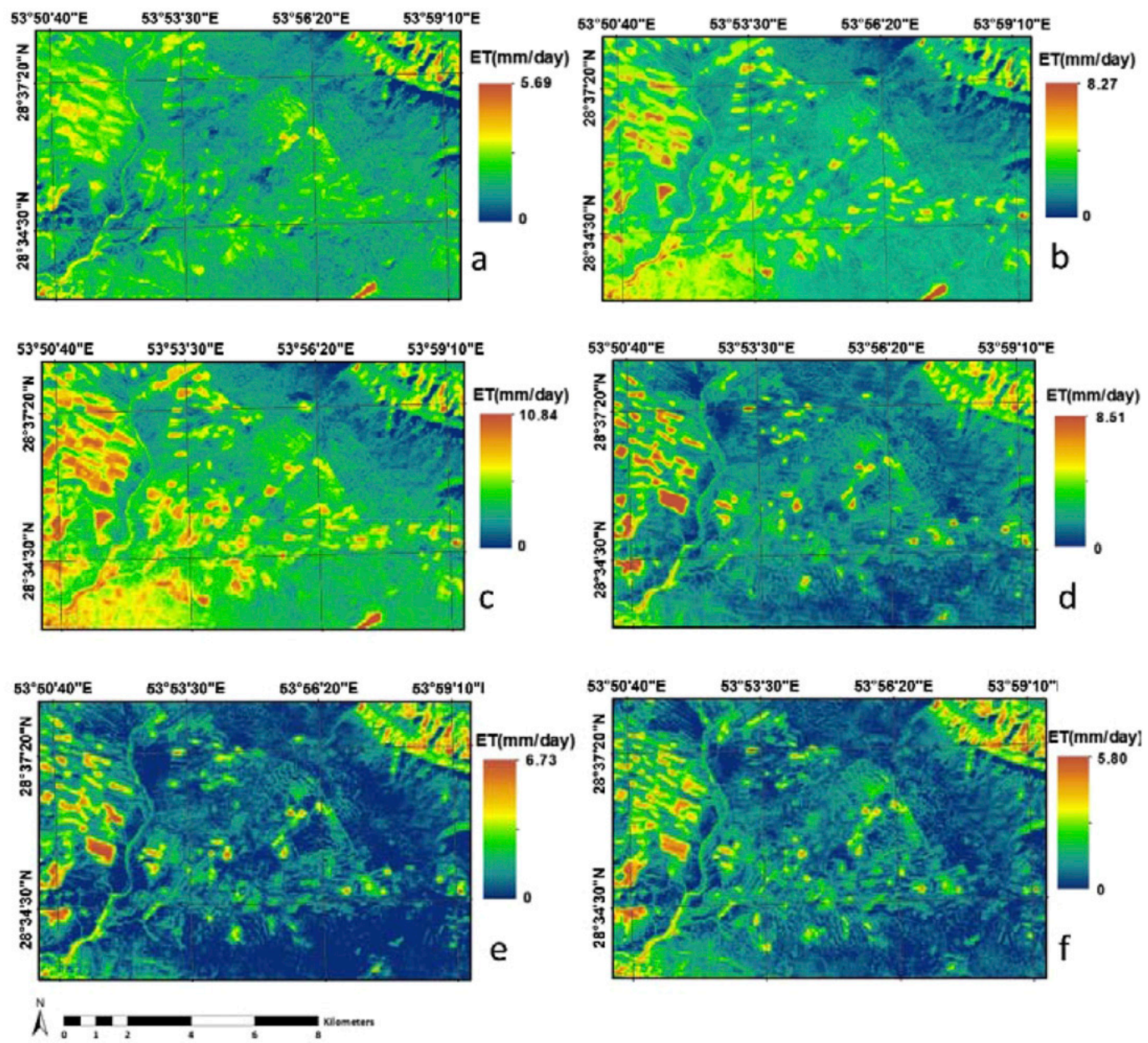

FIG. 7. Daily actual ET map generated with the METRIC model for (a) 22 Jan, (b) 23 Feb, (c) 18 Mar, (d) 11 Jun, (e) 28 Oct, and (f) 6 Nov 2010. 

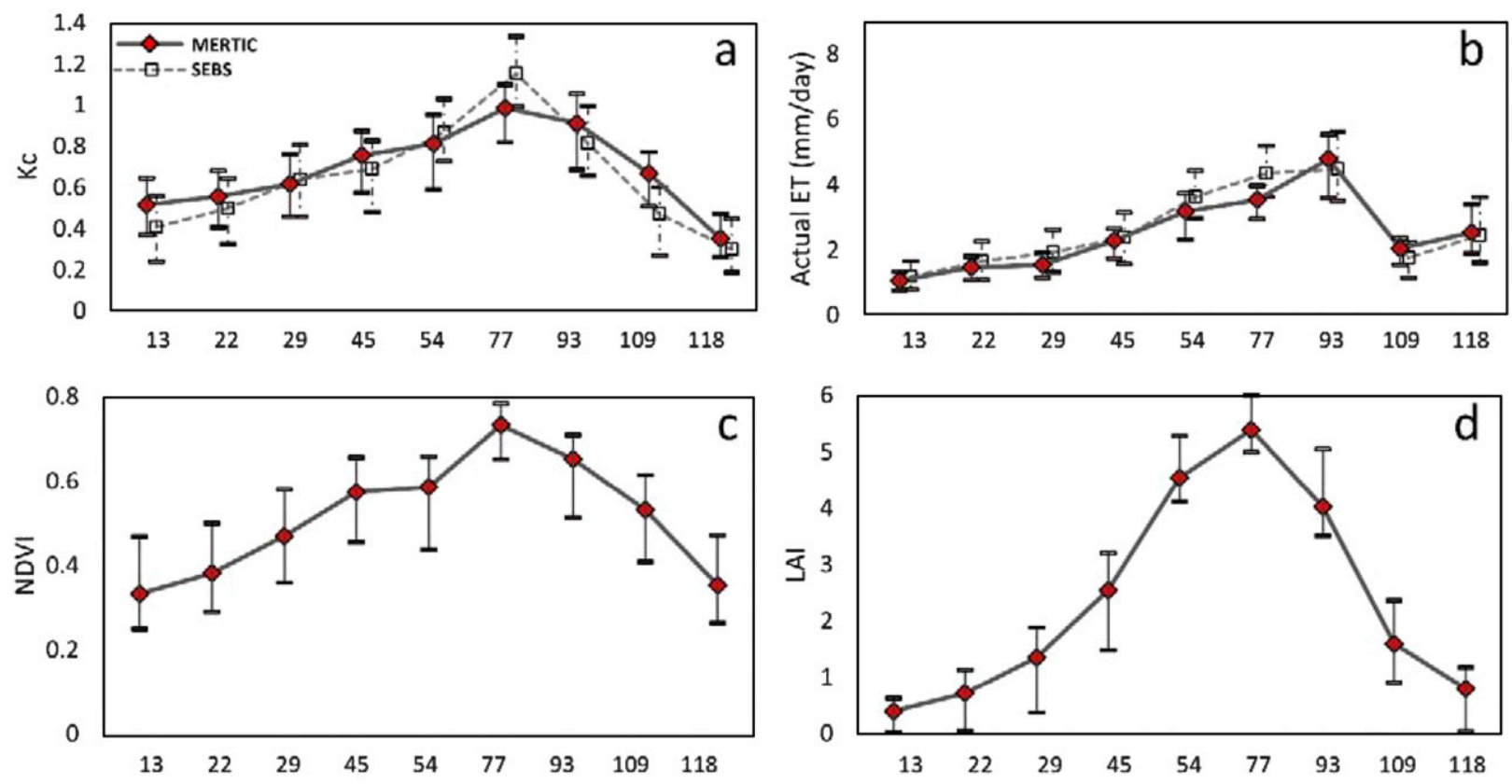

FIG. 8. Seasonal variation of (a) crop coefficient, (b) actual evapotranspiration, (c) NDVI, and (d) LAI for wheat resulting from the METRIC and SEBS models, corresponding to the day of year for which Landsat images were available.

type and occurred when using Landsat imageries; nevertheless, both model estimates were relatively good.

\section{c. Estimates of regional crop coefficient $K_{c}$, NDVI, and LAI}

While $\mathrm{ET}_{a}$ has spatiotemporal variability and is typically a difficult parameter to compare across different locations, average crop coefficients $K_{c}$ can be considered more transferable (Allen et al. 1998). We estimate $\mathrm{ET}_{\mathrm{rF}}$, based on the crop coefficient $K_{c}$ that reflects the crop state and the stress condition related to water or soil stress $\left(K_{c} \times K_{s}\right)$. To calculate the average value of $K_{c}$, each agricultural field pixel was identified and $K_{c}$ values were calculated and extracted. For each day during growing seasons the values were averaged (simple average over all pixels), and the mean values obtained for each day were then averaged over the entire growing seasons.

For winter cropping season with wheat as the main crop, the calculated $K_{c}$ ranged from 0.52 in its initial growing stage and peaked to around 1.15 during March, when the maximum canopy greenness occurred. The $K_{c}$ value again reduced to around 0.35 prior to harvest. SEBS estimated the average $K_{c \text {-mid }}$ value of 1.21, which was greater than the METRIC estimation (1.15). Comparing the $K_{c}$ values from the two models (Fig. 8a), lower uncertainty ( $15 \%$ on average) was obtained from the METRIC model. Better parameterization and in particular, the self-calibration process in the METRIC model, resulted in the lower uncertainties in the final estimates (i.e., $\mathrm{ET}_{\mathrm{rF}}$ or $K_{c}$ ) compared to the SEBS model. The mean $K_{c \text {-mid }}$ values of 1.21 and 1.15 , for SEBS and METRIC respectively, are consistent with the typical values reported in a variety of bioclimates, which range from 1.08 to 1.19 (e.g., Bandyopadhyay and Mallick 2003; Gao et al. 2009; Ko et al. 2009; Zhao et al. 2013). In particular, Niazi et al. (2005) reported $K_{c \text {-mid }}$ values of 1.09-1.13 for Fars Province, which encompasses the study area. The area is relatively dry, with high temperatures and winds during the midseason, and higher values of $K_{c}$ are typically expected. The difference in $K_{c}$ could also be due to crop varieties and crop management practices.

For the summer season with corn as the main crop, METRIC estimated the average midseason $K_{c}$ values as 1.16, whereas the SEBS-based estimate was at 1.08 (Fig. 9a). These values were well compared with those reported in the literature. A ranging value of 1.08-1.20 was reported by Allen et al. (1998), Liu and Pereira (2000), Gao et al. (2009), Martínez-Cob (2008), and Zhao et al. (2013). Similar to the study region, Gheysary et al. (2006) reported $K_{c \text {-mid }}$ of 1.13 for a study implemented at Varamin, south of Tehran with the same mean temperature and annual rainfall. As a result, the $K_{c}$ values obtained appear to be appropriate for farms in this region with forage corn crops.

Considering the different crops and vegetation cover over the study area, a temporally averaged $K_{c}$ value 

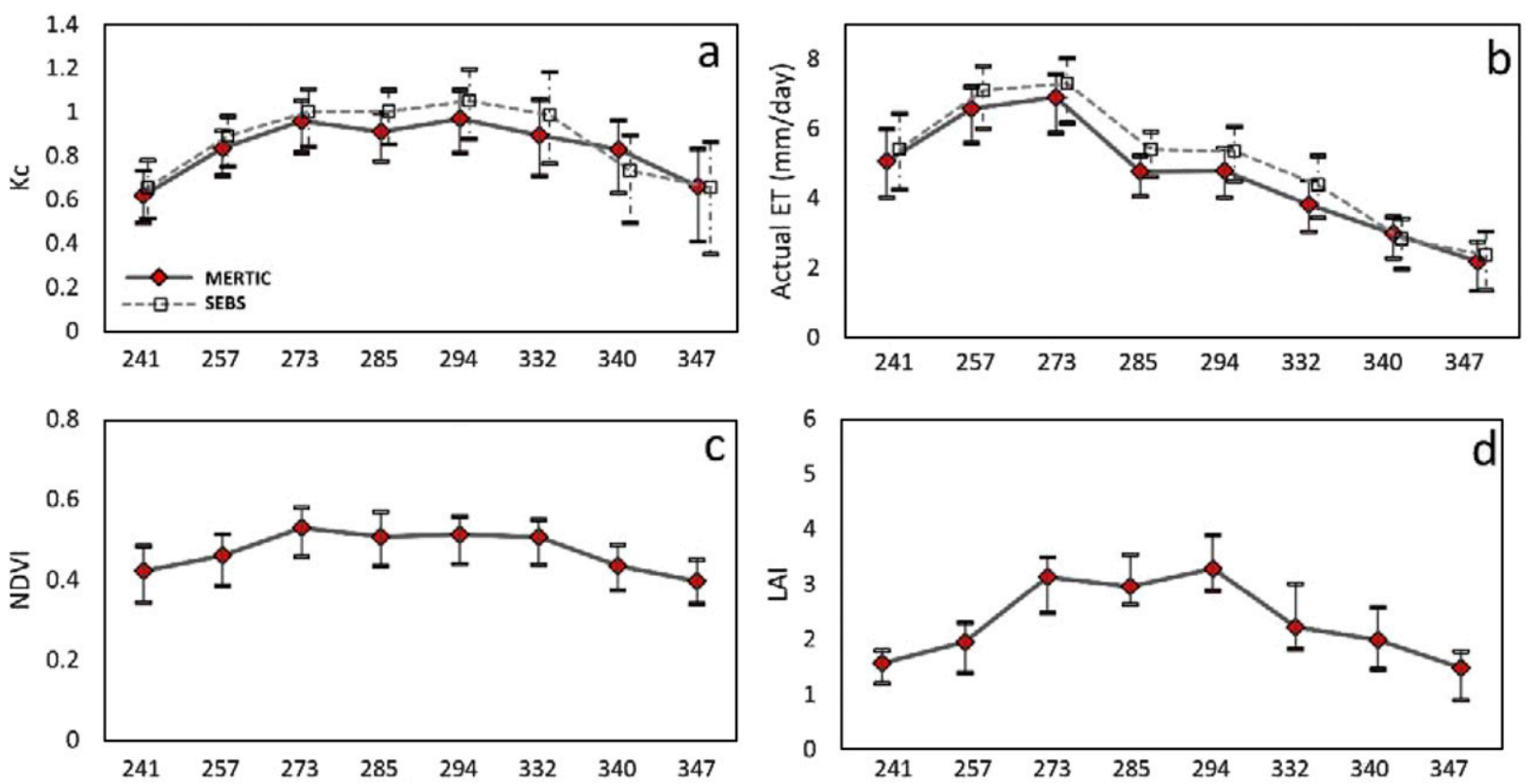

FIG. 9. Seasonal variation of (a) crop coefficient, (b) actual evapotranspiration, (c) NDVI, and (d) LAI for corn as obtained from the METRIC and SEBS models, corresponding to the day of year for which Landsat images were available.

of 0.77 was obtained for the region. The summertime average was 0.84 (ranged from 0.66 to 0.96 ), while in wintertime the $K_{c}$ values estimated as 0.68 (ranged from 0.52 to 0.82 ). This landscape coefficient value can be effectively used with $\mathrm{ET}_{r}$ estimates from simpler equations such as the Penman-Monteith approach to generate the actual ET for the entire landscape during a cropping season. This approach is expected to help assess the crop water usage and the broader agricultural water consumption and help the growers and water managers have a better outlook regarding water requirements through the growing season.

The NDVI and LAI values obtained from the METRIC and the SEBS models were similar (Figs. 8, 9), since we use the same formulation in both the models. Based on the available Landsat images, the average NDVI for wheat was 0.33 (13 January 2010), which peaked to 0.73 (18 March 2010) before falling to 0.35 (28 April 2010) close to harvest. The average LAI for the corresponding dates ranged from $0.4,5.4$, and 0.8 , respectively. The average NDVI for forage was 0.42 (29 August 2010), 0.55 (30 September 2010) at the peak of the season and then dropped to 0.39 (13 November 2010) close to harvest. The corresponding average LAI was $1.6,3.5$, and 1.3 , respectively. The seasonal variability for NDVI and LAI are presented in Figs. 8c, 8d, 9c, and 9d. The maximum ET for wheat occurred during March with average rate of $4.2 \mathrm{~mm} \mathrm{day}^{-1}$, and for forage corn occurred during September with average rate of $6.7 \mathrm{~mm}$ day $^{-1}$ (Figs. 8b, 9b).

\section{d. Comparison of reference ET methods from the REF-ET tool}

The differences between measured values and calculated ones were plotted for the standard form of the American Society of Civil Engineers (ASCE) PenmanMonteith (Allen 2000) since it showed the lowest RMSE; also plotted are values from two methods, FAO24 radiation (Doorenbos and Pruitt (1977)) and Makkink (1957), to illustrate the range of values from the different methods (Fig. 10). According to calculated values for RMSE, Standard Penman Monteith (Allen et al. 1998), FAO-56 (Allen et al. 1998), KimberlyPenman (Wright 1982), and Penman (Penman 1963) showed better accuracy for calculating $\mathrm{ET}_{r}$. To cover the dates with missing pan data, we chose Standard Penman Monteith (PMst) to calculate $\mathrm{ET}_{r}$ as the basis for comparisons and other computations.

The REF-ET tool presents a computationally easy approach in regard to running the model. The challenge here is that REF-ET generates reference ET and not the actual ET. This would pose an impediment for local agencies and communities that need actual ET for different crop landscapes. To address this, we used the outcome from METRIC and SEBS to estimate a general $K_{c}$ term (as described above). The landscape $K_{c}$ values that resulted from the models were incorporated with 


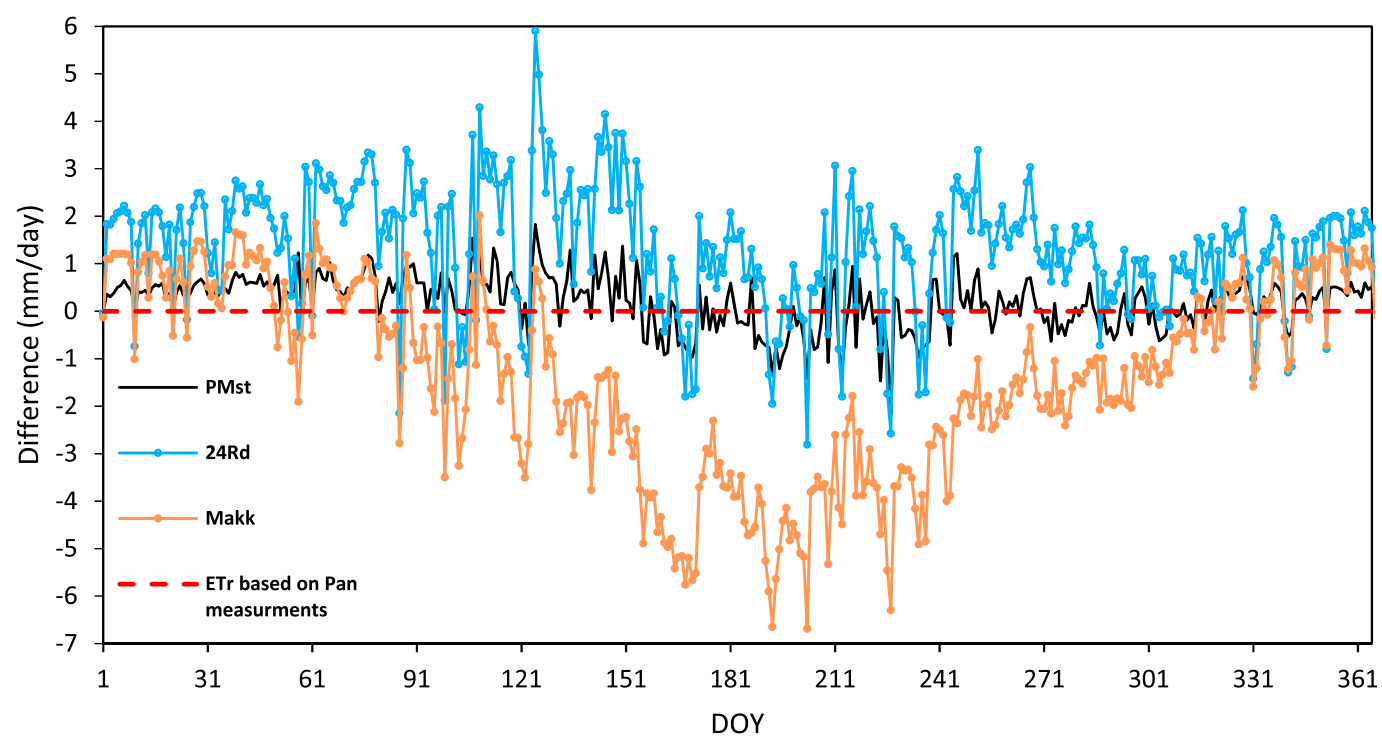

FIG. 10. The difference between time series of $\mathrm{ET}_{r}$ calculated with the REF-ET tool and measured pan evaporation.

the reference ET values that resulted from the REF-ET tool to generate actual ET for the study region as the hybrid method. This method estimated seasonal crop water use as of $5.05 \mathrm{Mm}^{3}$ for the winter season and $4.82 \mathrm{Mm}^{3}$ for the summer season (Fig. 11a). The hybrid method underestimated the measured values; however, with $7.1 \%$ and $9.5 \%$ of error (Fig. 11b) for winter and summer seasons, respectively, it generated satisfactory results as both METRIC and SEBS.

\section{e. Short incoming solar radiation}

As can be seen in Fig. 12, the equations used in METRIC and SEBS approaches overestimated the solar radiation, while CMSAF and r.sun values remained closer to the measured data. In previous studies (Nguyen and Pearce 2010; Pakparvar et al. 2014), the r.sun approach was used and the results were satisfactory. The daily averaged RMSE value of $70 \mathrm{~W} \mathrm{~m}^{-2}$ between the observations and the CMSAF product nominated it as the preferred radiation input for our models. Figure 13 shows the comparison for hourly data for select dates. The evaluation of CMSAF data from this study highlights its suitability to be used as SISR input when measurements are not available.

\section{Conclusions}

The motivation for this study was to assess the multiscale ET estimation approaches with a broader objective to aid local decision-makers and border communities, for example, over GBP, southern Iran, and providing a guideline for developing tools that can be used for design, water management, and water sustainability for the study region and the broader regions with similar characteristics (e.g., MENA region).
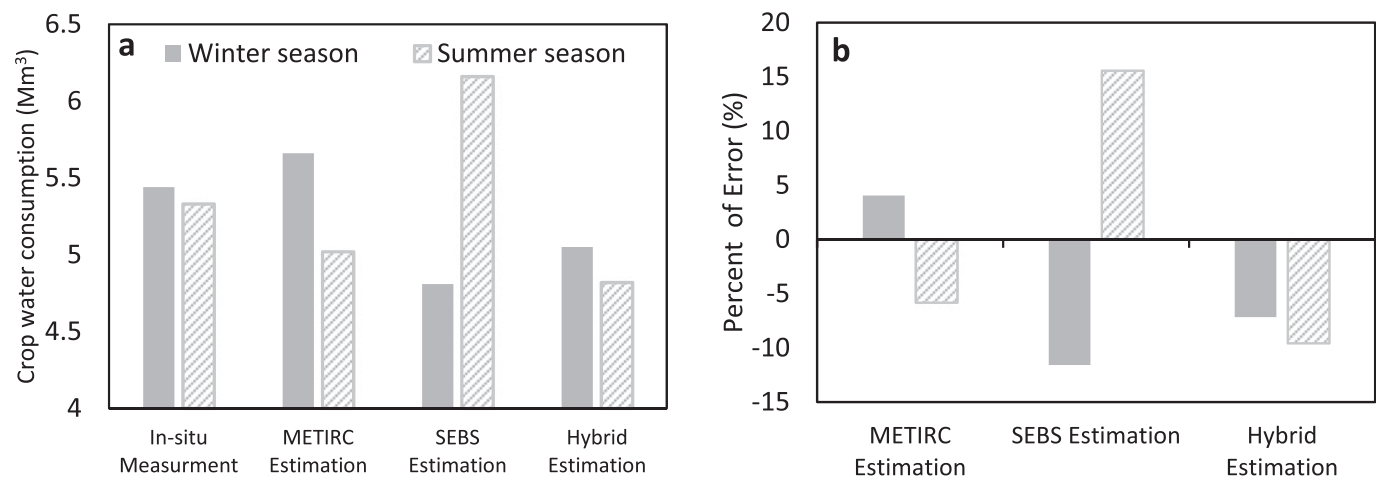

FIG. 11. (a) Comparison between in situ measurements and the models estimation of crop water use for the growing seasons. (b) Error percentage that resulted from the models. 


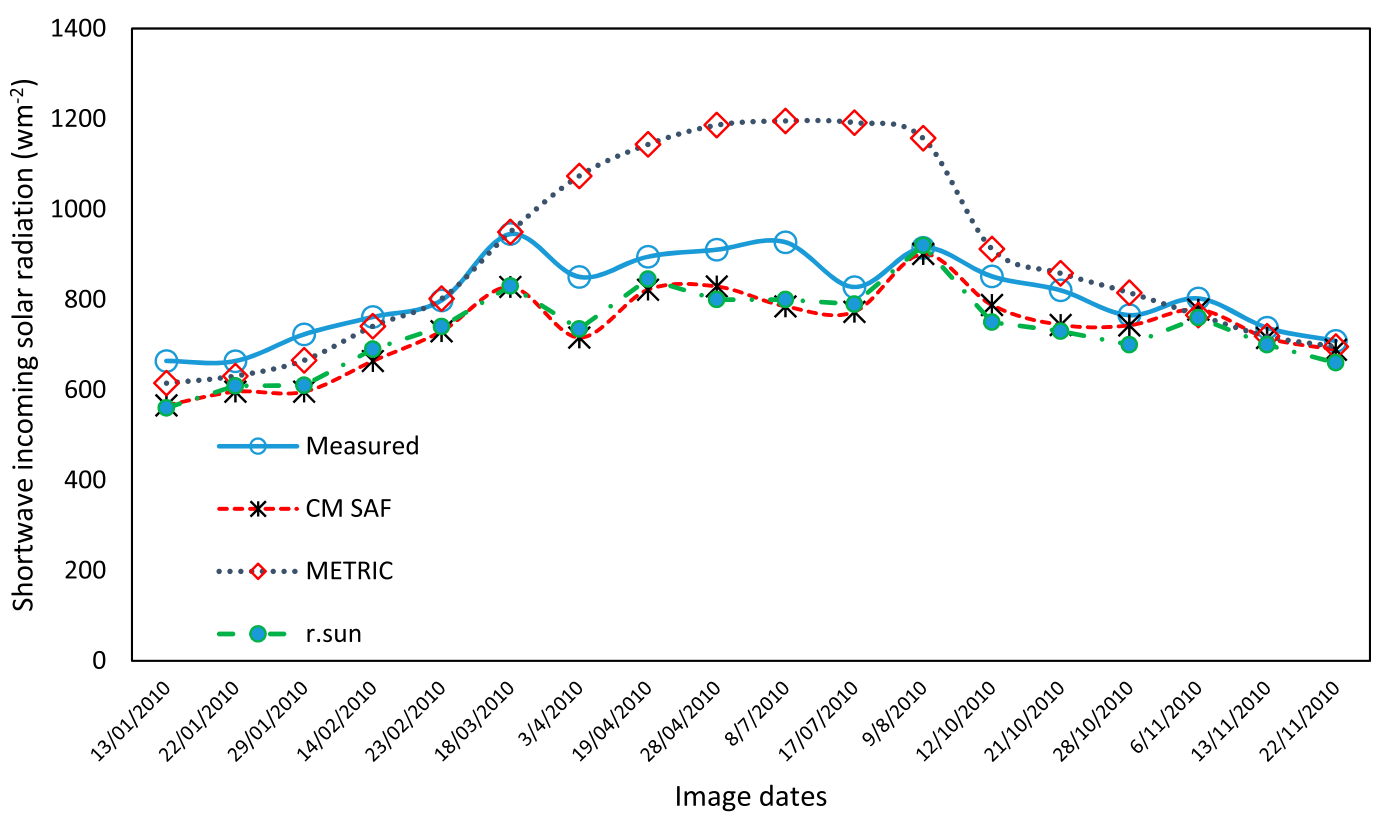

FIG. 12. Comparison of SISR obtained from METRIC, CMSAF, r.sun, and measured data.

Results indicated that for generating locally and regionally usable ET estimates, higher spatial resolution increases the ability of ET estimates to be more relevant. Reanalysis products, while providing a relatively easily accessible source, were inadequate and underestimated the ET values. This underestimation was likely due to the coarse resolution and because the reanalysis products did not capture representative surface features. As a result, reanalysis products, while popular, were deemed uncertain in the study region. While the NCEP reanalysis had a relatively better performance of the different products evaluated, the overall inability of reanalysis products to be adequate for the region led to the conclusion that high-resolution, local-scale ET estimates need to be developed to enable useful and usable decision tools for the community. The postprocessed Landsat-based fields used with METRIC and SEBS models were found to provide relatively good and representative ET estimates. The SEBS algorithm needed simpler parameterizations, but less validated when compared to METRIC/SEBAL, particularly for datasparse regions with semiarid to arid climate. The SEBS model showed higher uncertainty (15\% on average) compared to the METRIC model in which better parameterization and in particular, the self-calibration process, resulted in the lower uncertainties in land data, and it has shown promising results with the caveat that some local calibrations were required to make the approach more objective and repeatable. The study results were used for estimating regional $K_{c}$ values which can be combined with easily usable methods to calculate reference ET. Solar radiation is a key input to ET estimates, yet difficult to obtain in regions with paucity of in situ observations. The CMSAF data, which provide remotely sensed solar radiation products, were evaluated and found to be a reliable source of SISR parameter that enhances the accuracy of ET calculations.

The study conclusion provides a guideline for developing a framework in which actual ET can be estimated using a simple hybrid approach for the study region with limited availability of in situ data. To that end, satellite datasets can be used for generating average regionally representative landscape coefficient values. The landscape coefficient (averaged $K_{c}$ values) can then be used efficiently with simple equations such as Penman-Monteith or climatology ET models to generate regionally representative, easily accessible, and reliable long-term ET estimates for the region. Such estimates can provide the basis for a reliable and usable decision tool in the long run. Local growers and water managers can use the outcome of this study to assess water usage by crops and improve their decision-making tools. Accordingly, the suggested framework can be adopted for a similar domain that is data sparse with limited access to in situ observations. The framework considers three parts. (i) For the region of interest, multiscale ET products can be tested ranging from reanalysis to satellite. More accurate products or models can be customized (e.g., using CMSAF data), and a simplified outcome can be introduced based on the analysis of the models or products to be more usable for the local community of region. (ii) Parametric values 

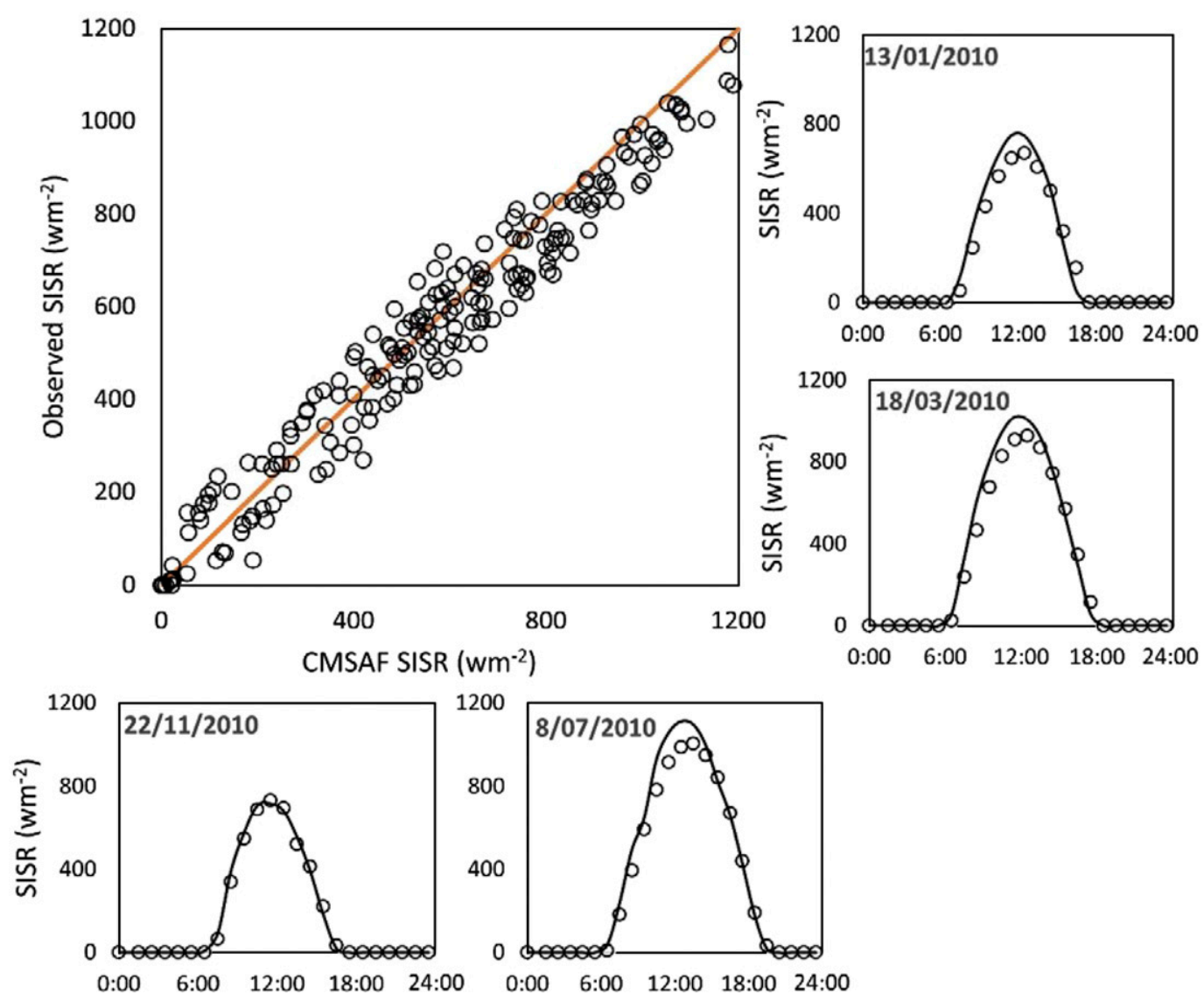

FIG. 13. Comparison of SISR obtained from CMSAF and hourly measurements for all data as well as examples of diurnal changes for select dates.

can be identified that are required by relatively simple models (which in this case was the REF-ET tool). (iii) The tool and simplified outcome then can be used together to provide estimates that could be relevant, reliable, and locally representative in a longer context.

It should be highlighted that in the study region reliable measured in situ data were difficult to obtain and therefore, the spatial scale of this study is limited to the GBP. Further studies and in situ observations considering other regions and growing seasons need to be conducted to bolster the results.

\section{REFERENCES}

Allan, J. A., and T. Allan, 2002: The Middle East Water Question: Hydropolitics and the Global Economy. I.B. Tauris, $382 \mathrm{pp}$.

Allen, R. G., 2000: REF-ET: Reference evapotranspiration calculation software for FAO and ASCE standardized equations. University of Idaho, 82 pp., https://www.webpages.uidaho.edu/ ce325/references/manual_prn.pdf.

, L. S. Pereira, D. Raes, and M. Smith, 1998: Crop evapotranspiration: Guidelines for computing crop water requirements. FAO Irrigation and Drainage Paper 56, 300 pp., www.fao.org/docrep/X0490E/X0490E00.htm.
—, M. Tasumi, and R. Trezza, 2007: Satellite-based energy balance for mapping evapotranspiration with internalized calibration (METRIC) —Model. J. Irrig. Drain. Eng., 133, 380394, https://doi.org/10.1061/(ASCE)0733-9437(2007)133:4(380).

Anderson, M. C., C. Hain, B. Wardlow, A. Pimstein, J. R. Mecikalski, and W. P. Kustas, 2011: Evaluation of drought indices based on thermal remote sensing of evapotranspiration over the continental United States. J. Climate, 24, 20252044, https://doi.org/10.1175/2010JCLI3812.1.

Aubinet, M., 2008: Eddy covariance $\mathrm{CO}_{2}$ flux measurements in nocturnal conditions: an analysis of the problem. Ecol. Appl., 18, 1368-1378, https://doi.org/10.1890/06-1336.1.

Baldocchi, D. D., 2003: Assessing the eddy covariance technique for evaluating carbon dioxide exchange rates of ecosystems: Past, present and future. Global Change Biol., 9, 479-492, https://doi.org/10.1046/j.1365-2486.2003.00629.x.

Bandyopadhyay, P. K., and S. Mallick, 2003: Actual evapotranspiration and crop coefficients of wheat (Triticum aestivum) under varying moisture levels of humid tropical canal command area. Agric. Water Manage., 59, 33-47, https://doi.org/ 10.1016/S0378-3774(02)00112-9.

Bastiaanssen, W. G. M., M. Menenti, R. A. Feddes, and A. A. M. Holtslag, 1998: A remote sensing surface energy balance algorithm for land (SEBAL). 1. Formulation. J. Hydrol., 212213, 198-212, https://doi.org/10.1016/S0022-1694(98)00253-4.

Bengtsson, L., K. I. Hodges, and S. Hagemann, 2004: Sensitivity of the ERA40 reanalysis to the observing system: 
determination of the global atmospheric circulation from reduced observations. Tellus, 56A, 456-471, https://doi.org/ 10.3402/tellusa.v56i5.14466.

Doorenbos, J., and W. O. Pruitt, 1977: Crop water requirements. FAO Irrigation Drainage Paper 24, 154 pp., http://www.fao.org/ 3/a-f2430e.pdf.

Droogers, P., W. Immerzeel, W. Terink, J. Hoogeveen, M. Bierkens, L. van Beek, and B. Negewo, 2012: Modeling water resources trends in Middle East and North Africa towards 2050. Hydrol. Earth Syst. Sci., 16, 3101-3114, https://doi.org/10.5194/ hess-16-3101-2012.

El Kharraz, J., A. El-Sadek, N. Ghaffour, and E. Mino, 2012: Water scarcity and drought in WANA countries. Procedia Eng., 33, 14-29, https://doi.org/10.1016/j.proeng.2012.01.1172.

Esmaeili, A., and S. Vazirzadeh, 2009: Water pricing for agricultural production in the South of Iran. Water Resour. Manage., 23, 957-964, https://doi.org/10.1007/s11269-008-9308-y.

Fall, S., D. Niyogi, A. Gluhovsky, R. A. Pielke, E. Kalnay, and G. Rochon, 2010: Impacts of land use land cover on temperature trends over the continental United States: Assessment using the North American Regional Reanalysis. Int. J. Climatol., 30, 1980-1993, https://doi.org/10.1002/joc.1996.

Faramarzi, M., K. Abbaspour, R. Schulin, and H. Yang, 2009: Modelling blue and green water resources availability in Iran. Hydrol. Processes, 23, 486-501, https://doi.org/10.1002/hyp.7160.

Fisher, J. B., R. J. Whittaker, and Y. Malhi, 2011: ET come home: Potential evapotranspiration in geographical ecology. Global Ecol. Biogeogr., 20, 1-18, https://doi.org/10.1111/ j.1466-8238.2010.00578.x.

Frere, M., and G. F. Popov, 1979: Agrometeorological crop monitoring and forecasting. FAO Plant Production and Protection 17, FAO, 38-43.

Gao, Y., A. Duan, J. Sun, F. Li, Z. Liu, H. Liu, and Z. Liu, 2009: Crop coefficient and water-use efficiency of winter wheat/ spring maize strip intercropping. Field Crop. Res., 111, 65-73, https://doi.org/10.1016/j.fcr.2008.10.007.

Gheysary, M., M. Mirlatifi, M. Homaee, and M. Asadi, 2006: Determination of Crop Water Use and Crop Coeficient of Corn Silage Based on Crop Growth Stages (in Farsi with English abstract). J. Agric. Eng. Res., 7, 125-142.

Ghilain, N., A. Arboleda, and F. Gellens-Meulenberghs, 2011: Evapotranspiration modelling at large scale using near-real time MSG SEVIRI derived data. Hydrol. Earth Syst. Sci., 15, 771-786, https://doi.org/10.5194/hess-15-771-2011.

Gibson, B., S. Hassan, and J. Tansey, 2013: Sustainability Assessment: Criteria and Processes. Routledge, $268 \mathrm{pp}$.

Haddadin, M. J., 2001: Water scarcity impacts and potential conflicts in the MENA region. Water Int., 26, 460-470, https:// doi.org/10.1080/02508060108686947.

Hakimian, H., 2003: Water scarcity and food imports: An empirical investigation of the virtual water hypothesis in the MENA region. Rev. Middle East Econ. Finance, 1, 71-85, https:// doi.org/10.1080/1475368032000061653.

Hargreaves, G. H., and Z. A. Samani, 1985: Reference crop evapotranspiration from temperature. Appl. Eng. Agric., 1 96-99, https://doi.org/10.13031/2013.26773.

Hu, G., L. Jia, and M. Menenti, 2015: Comparison of MOD16 and LSA-SAF MSG evapotranspiration products over Europe for 2011. Remote Sens. Environ., 156, 510-526, https://doi.org/ 10.1016/j.rse.2014.10.017

Irmak, S., I. Kabenge, D. Rudnick, S. Knezevic, D. Woodward, and M. Moravek, 2013: Evapotranspiration crop coefficients for mixed riparian plant community and transpiration crop coefficients for Common reed, Cottonwood and Peach-leaf willow in the Platte River Basin, Nebraska-USA. J. Hydrol., 481, 177-190, https://doi.org/10.1016/j.jhydrol.2012.12.032.

Jamshidi, S., S. Zand-Parsa, M. Naghdyzadegan Jahromi, and D. Niyogi, 2019: Application of a simple Landsat-MODIS fusion model to estimate evapotranspiration over a heterogeneous sparse vegetation region. Remote Sens., 11, 741, https://doi.org/10.3390/rs11070741.

Kamali, H., and S. Zand-Parsa, 2017: Estimation of sugar beet yield and its dry matter partitioning under different irrigation and nitrogen levels. Mod. Appl. Sci., 11, 141-156, https://doi.org/ 10.5539/mas.v11n1p143.

Kim, J., and T. S. Hogue, 2012: Evaluation and sensitivity testing of a coupled Landsat-MODIS downscaling method for land surface temperature and vegetation indices in semi-arid regions. J. Appl. Remote Sens., 6, 063569, https://doi.org/10.1117/ 1.JRS.6.063569.

Kiptala, J. K., Y. Mohamed, M. L. Mul, and P. Zaag, 2013: Mapping evapotranspiration trends using MODIS and SEBAL model in a data scarce and heterogeneous landscape in Eastern Africa. Water Resour. Res., 49, 8495-8510, https://doi.org/ 10.1002/2013WR014240

Ko, J., G. Piccinni, T. Marek, and T. Howell, 2009: Determination of growth-stage-specific crop coefficients $(\mathrm{Kc})$ of cotton and wheat. Agric. Water Manage., 96, 1691-1697, https://doi.org/ 10.1016/j.agwat.2009.06.023

Kongo, V. M., and G. P. W. Jewitt, 2006: Preliminary investigation of catchment hydrology in response to agricultural water use innovations: A case study of the Potshini catchment-South Africa. Phys. Chem. Earth, 31, 976-987, https://doi.org/ 10.1016/j.pce.2006.08.014.

Kustas, W. P., and C. S. T. Daughtry, 1990: Estimation of the soil heat flux/net radiation ratio from spectral data. Agric. For. Meteor., 49, 205-223, https://doi.org/10.1016/0168-1923(90)90033-3.

Liang, X., J. Guo, and L. R. Leung, 2004: Assessment of the effects of spatial resolutions on daily water flux simulations. J. Hydrol., 298, 287-310, https://doi.org/10.1016/ j.jhydrol.2003.07.007.

Liu, Y., and L. S. Pereira, 2000: Validation of FAO methods for estimating crop coefficients. Nongye Gongcheng Xuebao, 16, 26-30.

Liu, S. M., Z. W. Xu, Z. L. Zhu, Z. Z. Jia, and M. J. Zhu, 2013: Measurements of evapotranspiration from eddy-covariance systems and large aperture scintillometers in the Hai River Basin, China. J. Hydrol., 487, 24-38, https://doi.org/10.1016/ j.jhydrol.2013.02.025.

Long, D., and V.P. Singh, 2013: Assessing the impact of end-member selection on the accuracy of satellite-based spatial variability models for actual evapotranspiration estimation. Water Resour. Res., 49, 2601-2618, https://doi.org/10.1002/wrcr.20208.

Lorenz, C., and H. Kunstmann, 2012: The hydrological cycle in three state-of-the-art reanalyses: Intercomparison and performance analysis. J. Hydrometeor., 13, 1397-1420, https:// doi.org/10.1175/JHM-D-11-088.1.

Makkink, G., 1957: Testing the Penman formula by means of lysimeters. J. Inst. Water Eng., 11, 277-288.

Mao, Y., and K. Wang, 2017: Comparison of evapotranspiration estimates based on the surface water balance, modified Penman-Monteith model, and reanalysis data sets for continental China. J. Geophys. Res. Atmos., 122, 3228-3244, https:// doi.org/10.1002/2016JD026065.

Martínez-Cob, A., 2008: Use of thermal units to estimate corn crop coefficients under semiarid climatic conditions. Irrig. Sci., 26, 335-345, https://doi.org/10.1007/s00271-007-0097-5. 
Menenti, M., 1984: Physical aspects and determination of evaporation in deserts applying remote sensing techniques. Ph.D thesis, Wageningen University, 202 pp.

Mu, Q., F. A. Heinsch, M. Zhao, and S. W. Running, 2007: Development of a global evapotranspiration algorithm based on MODIS and global meteorology data. Remote Sens. Environ., 111, 519-536, https://doi.org/10.1016/j.rse.2007.04.015.

, M. Zhao, and S. W. Running, 2011: Improvements to a MODIS global terrestrial evapotranspiration algorithm. Remote Sens. Environ., 115, 1781-1800, https://doi.org/10.1016/ j.rse.2011.02.019.

Nazemosadat, M. J., and A. R. Ghasemi, 2004: Quantifying the ENSO-related shifts in the intensity and probability of drought and wet periods in Iran. J. Climate, 17, 4005-4018, https://doi.org/ 10.1175/1520-0442(2004)017<4005:QTESIT > 2.0.CO;2.

Nguyen, H. T., and J. M. Pearce, 2010: Estimating potential photovoltaic yield with $r$. sun and the open source geographical resources analysis support system. Sol. Energy, 84, 831-843, https://doi.org/10.1016/j.solener.2010.02.009.

Niazi, J., H. R. Fooladmand, S. H. Ahmadi, and J. Vaziri, 2005: Water requirement and crop coefficient of wheat in Zarghan area, Fars province. J. Sci. Technol. Agric. Nat. Resour, 9, 1-8.

Noshadi, M., and S. Jamshidi, 2014: Modification of water movement equations in the PRZM3 for simulating pesticides in soil profile. Agric. Water Manage., 143, 38-47, https://oi.org/10.1016/ j.agwat.2014.04.011.

Pakparvar, M., W. Cornelis, L. S. Pereira, D. Gabriels, H. Hosseinimarandi, M. Edraki, and S. A. Kowsar, 2014: Remote sensing estimation of actual evapotranspiration and crop coefficients for a multiple land use arid landscape of southern Iran with limited available data. J. Hydroinform., 16, 1441-1460, https://doi.org/10.2166/hydro.2014.140.

Penman, H. L., 1963: Vegetation and hydrology. Soil Sci., 96, 357, https://doi.org/10.1097/00010694-196311000-00014.

Priestley, C. H. B., and R. J. Taylor, 1972: On the assessment of surface heat flux and evaporation using large-scale parameters. Mon. Wea. Rev., 100, 81-92, https://doi.org/10.1175/ 1520-0493(1972)100<0081:OTAOSH > 2.3.CO;2.

Raziei, T., B. Saghafian, A. A. Paulo, L. S. Pereira, and I. Bordi, 2009: Spatial patterns and temporal variability of drought in western Iran. Water Resour. Manage., 23, 439, https://doi.org/ 10.1007/s11269-008-9282-4.

Rockström, J., M. Falkenmark, L. Karlberg, H. Hoff, S. Rost, and D. Gerten, 2009: Future water availability for global food production: The potential of green water for increasing resilience to global change. Water Resour. Res., 45, W00A12, https://doi.org/10.1029/2007WR006767.

Schmidt, G. A., and Coauthors, 2006: Present-day atmospheric simulations using GISS ModelE: Comparison to in situ, satellite, and reanalysis data. J. Climate, 19, 153-192, https:// doi.org/10.1175/JCLI3612.1.

Senay, G. B., S. Leake, P. L. Nagler, G. Artan, J. Dickinson, J. T. Cordova, and E. P. Glenn, 2011: Estimating basin scale evapotranspiration (ET) by water balance and remote sensing methods. Hydrol. Processes, 25, 4037-4049, https://doi.org/ 10.1002/hyp.8379.

Sepaskhah, A. R., and F. Razzaghi, 2009: Evaluation of the adjusted Thornthwaite and Hargreaves-Samani methods for estimation of daily evapotranspiration in a semi-arid region of Iran. Arch. Agron. Soil. Sci., 55, 51-66, https://doi.org/10.1080/ 03650340802383148 .
Su, H., M. F. McCabe, E. F. Wood, Z. Su, and J. H. Prueger, 2005: Modeling evapotranspiration during SMACEX: Comparing two approaches for local-and regional-scale prediction. J. Hydrometeor., 6, 910-922, https://doi.org/10.1175/ JHM466.1.

Su, Z., 2002: The Surface Energy Balance System (SEBS) for estimation of turbulent heat fluxes. Hydrol. Earth Syst. Sci., 6 , 85-100, https://doi.org/10.5194/hess-6-85-2002.

Tabari, H., and P. H. Talaee, 2011: Temporal variability of precipitation over Iran: 1966-2005. J. Hydrol., 396, 313-320, https://doi.org/10.1016/j.jhydrol.2010.11.034.

Trambauer, P., E. Dutra, S. Maskey, M. Werner, F. Pappenberger, L. P. H. van Beek, and S. Uhlenbrook, 2014: Comparison of different evaporation estimates over the African continent Hydrol. Earth Syst. Sci., 18, 193-212, https://doi.org/10.5194/ hess-18-193-2014.

Trenberth, K. E., J. T. Fasullo, and J. Mackaro, 2011: Atmospheric moisture transports from ocean to land and global energy flows in reanalyses. J. Climate, 24, 4907-4924, https://doi.org/ 10.1175/2011JCLI4171.1.

Turc, L., 1961: Evaluation des besoins en eau d'irrigation, evapotranspiration potentielle, formule climatique simplifice et mise a jour (in French). Ann. Agron., 12, 13-49.

Van der Kwast, J., and Coauthors, 2009: Evaluation of the Surface Energy Balance System (SEBS) applied to ASTER imagery with flux-measurements at the SPARC 2004 site (Barrax, Spain). Hydrol. Earth Syst. Sci., 13, 1337-1347, https://doi.org/ 10.5194/hess-13-1337-2009.

Vinukollu, R. K., E. F. Wood, C. R. Ferguson, and J. B. Fisher, 2011: Global estimates of evapotranspiration for climate studies using multi-sensor remote sensing data: Evaluation of three process-based approaches. Remote Sens. Environ., 115, 801-823, https://doi.org/10.1016/j.rse.2010.11.006.

Voss, K. A., J. S. Famiglietti, M. Lo, C. Linage, M. Rodell, and S. C. Swenson, 2013: Groundwater depletion in the Middle East from GRACE with implications for transboundary water management in the Tigris-Euphrates-Western Iran region. Water Resour. Res., 49, 904-914, https://doi.org/10.1002/ wrcr.20078.

Wang, W., P. Xie, S.-H. Yoo, Y. Xue, A. Kumar, and X. Wu, 2011: An assessment of the surface climate in the NCEP climate forecast system reanalysis. Climate Dyn., 37, 1601-1620, https://doi.org/10.1007/s00382-010-0935-7.

Weedon, G. P., G. Balsamo, N. Bellouin, S. Gomes, M. J. Best, and P. Viterbo, 2014: The WFDEI meteorological forcing data set: WATCH Forcing Data methodology applied to ERA-Interim reanalysis data. Water Resour. Res., 50, 7505-7514, https:// doi.org/10.1002/2014WR015638.

Wright, J. L., 1982: New evapotranspiration crop coefficients. ASCE J. Irrig. Drain. Div., 108, 57-74.

, 1996: Derivation of alfalfa and grass reference evapotranspiration, Evapotranspiration and Irrigation Scheduling: Proceedings of the International Conference, C. R. Camp, E. J. Sadler, and R. E. Yoder, Eds., American Society of Agricultural Engineers, $133-140$.

Yatagai, A., P. Xie, and P. Alpert, 2008: Development of a daily gridded precipitation data set for the Middle East. $A d v$. Geosci., 12, 165-170, https://doi.org/10.5194/adgeo-12-165-2008.

Zhao, N., Y. Liu, J. Cai, P. Paredes, R. D. Rosa, and L. S. Pereira, 2013: Dual crop coefficient modelling applied to the winter wheat-summer maize crop sequence in North China Plain: Basal crop coefficients and soil evaporation component. Agric. Water Manage., 117, 93-105, https://doi.org/10.1016/j.agwat.2012.11.008. 